\title{
Geologia Estrutural em ambiente rúptil: fundamentos físicos, mecânica de fraturas e sistemas de falhas naturais
}

\author{
Henrique Zerfass ${ }^{1}$, Farid Chemale $\mathrm{Jr}^{2}$ \\ ${ }_{1}^{1}$ Petróleo Brasileiro S/A, Univ. Petrobras, Escola de Ciência e \\ Tecnologia de E\&P-Rua Julio do Carmo 323, $8^{\circ}$ andar- CEP 20211 - \\ 260. Rio de Janeiro - RJ, henrique.zerfass@petrobras.com.br. \\ 2Instituto de Geociências, Universidade de Brasília, Campus Darcy \\ Ribeiro,Brasília, DF, fchemale@unb.br.
}

\begin{abstract}
Structural geology is a basic discipline in Geology courses, and has a wide application in different areas of a geologist's work field, either in the academy or industry. The traditional approach of structural geology is geometric-kinematic, in which rock stresses are induced from the geometry of structures. As a mean of enhancing the knowledge of the process-product relationship, this paper aims to add concepts of mechanics of solids to the study of brittle structures - fractures, joints and faults. It is discussed as an inverse reasoning the way natural structures can be deduced or predicted from the principles of mechanics. The starting points are the concepts of force, stress and strain. In the following are presented the principal ideas on initiation and propagation of fractures. This knowledge was constructed by theoretical principles (Mohr-Coulomb Theory) as well as through observation and measuring by performing laboratory tests. In addition, the role of fracture linkage in the formation of joints and faults systems is discussed. Natural fault systems of extensional, compressional and transcurrent environments are briefly revised based on the concepts previously presented. The principles of the mechanics of solids herein discussed yield a relevant contribution to interpret the natural brittle structures. Citation: Zerfass H., Chemale jr. F. 2011. Geologia estrutural em ambiente rúptil: fundamentos físicos, mecânica de fraturas e sistemas de falhas naturais. Terræ Didatica, $7(1): 75-85<$ http://www. .ge.unicamp.br/terraedidatica/>
\end{abstract}

KEYWORDS Force, stress, fracture mechanics, joints, faults, fractures

RESUMO A geologia estrutural é uma matéria fundamental para o currículo de Geologia, com aplicações nas mais diferentes áreas de atuação do geólogo, tanto em atividades acadêmicas como industriais. Tradicionalmente, a geologia estrutural tem enfoque geométrico-cinemático, em que os esforços sofridos pelas rochas são induzidos a partir da disposição geométrica das estruturas. Como forma de agregar conhecimento da relação-processo-produto, este artigo procura adicionar conceitos de mecânica dos sólidos ao estudo das estruturas rúpteis - fraturas, juntas e falhas. Seguindo-se o raciocínio inverso, discute-se como as estruturas naturais podem ser deduzidas ou previstas a partir dos princípios da mecânica. $O$ ponto de partida são os conceitos de força, tensão e magnitude de deformação. A partir daí, são apresentadas as principais ideias sobre a formação e propagação de fraturas, que foram desenvolvidas através de princípios teóricos (Teoria de Mohr-Coulomb), bem como pela observação e medição de parâmetros durante ensaios de laboratório. Também será abordado o tema da ligação de fraturas, e o seu papel na formação dos sistemas de juntas e falhas. Os sistemas de falhas naturais em ambiente distensional, compressional e transcorrente são então brevemente revistos com base nos conceitos anteriormente apresentados. Os princípios da mecânica dos sólidos aqui discutidos contribuem de forma relevante para a interpretação das estruturas rúpteis naturais.

PALAVRAS-CHAVE Força, tensão, mecânica de fraturas, juntas, falhas, fraturas 


\section{Introdução}

$\mathrm{Na}$ disciplina de geologia estrutural das escolas de geologia, em geral o conteúdo programático trata da observação, descrição e interpretação das feições estruturais observadas em afloramentos ou lâminas delgadas. Esta é a forma como classicamente o assunto tem sido tratado, e como a própria disciplina de geologia estrutural se desenvolveu ao longo de um século.

Conforme mencionado por Mandl (1988), esta é a abordagem geométrica e cinemática. Um grande número de livros-texto sobre geologia estrutural foi gerado com base nesta visão.

Menos desenvolvida no meio geológico é a abordagem mecânica. Isto talvez se deva, em parte, ao fato de que os cursos de geologia são em geral voltados para o mapeamento geológico, dando-se ênfase ao reconhecimento de estruturas em campo e sua interpretação expedita. Além disso, a mecânica de rochas se encontra em uma interface com a engenharia de materiais, e boa parte do material bibliográfico na área tem enfoque a partir desta última. Isto não seria um problema não fosse a questão de que as finalidades da engenharia de materiais e da geologia estrutural são distintas: enquanto a primeira estuda as condições que provocam deformação dos materiais, a fim de evitá-las ou minimizá-las, a segunda se volta para os materiais naturalmente deformados a fim de construir sua história de deformação.

A importância da abordagem mecânica reside no fato de que o conhecimento teórico e laboratorial dos processos envolvidos na deformação das rochas enriquece a construção de hipóteses de trabalho a serem aplicadas às rochas deformadas. Para Mandl (1988), a abordagem 'geométrica-cinemática' baseia-se em demasia nas analogias entre modelos geológicos, tornando difícil avaliar se as feições em comum implicam correspondência de processos tectônicos ou se são apenas similaridades superficiais.

O objetivo deste artigo é familiarizar o leitor com a abordagem mecânica, porém mantendo-se o foco na geologia estrutural e nas habilidades e competências do geólogo nesta área de atuação. Assim, procura-se desenvolver os fundamentos da mecânica aplicada às rochas desde os conceitos físicos fundamentais, os quais estão implícitos nas discussões mais sofisticadas, até chegar aos sistemas de fraturas no ambiente crustal.

\section{Fundamentos físicos}

A força é a grandeza física fundamental para o estudo da deformação das rochas. A definição física de força deve-se a Isaac Newton, no século XVII. No entanto, o conceito de força é mais antigo. Aristóteles, na sua obra Mecânica, associava o movimento dos corpos a forças, embora na sua concepção estas atuassem no sentido de manter o movimento (Einstein \& Infeld 1938). Os escolásticos da Idade Média explicavam mudanças de temperatura pela ação de uma força quente ou fria (Grigoryev \& Myakishev 1967).

Galileu Galilei e Isaac Newton desenvolveram as bases da mecânica clássica, na qual o movimento dos corpos era a questão mais importante. A Galileu se deve a ruptura com o senso comum de movimento, especialmente devido aos seus estudos de queda livre. Isto forneceu uma importante base para que Newton propusesse as leis da mecânica clássica.

De acordo com Cajori (1929), as primeiras reflexões de Newton tratavam da gravidade. Newton pensava que a mesma força que mantinha a Lua em órbita da Terra atuaria sobre a superfície da Terra como atração gravitacional; se a atração da Terra sobre os corpos se mantinha inalterável a despeito da altitude na Terra, a mesma poderia se estender até a Lua (Cajori 1929).

Em seu Philosophiae naturalis principia mathematica (Newton 1686), Isaac Newton refere-se a força como "a vis insita, ou força inata da matéria, (é) um poder de resistir, através do qual todo o corpo, estando em um determinado estado, mantém esse estado, seja ele de repouso ou de movimento uniforme em linha reta"; da mesma forma, Newton considerava força uma "ação" que "não permanece no corpo quando cessa a ação". Na mesma obra, Newton afirma que "a mudança de movimento é proporcional à força motora imprimida, e é produzida na direção da linha reta através da qual aquela força é imprimida".

A força é uma grandeza vetorial, com magnitude, direção e sentido. Duas ou mais forças atuando simultaneamente sobre um mesmo corpo podem ser combinadas em uma força resultante, assim como uma única força pode ser resolvida em dois ou mais componentes (Price \& Cosgrove 1990). Embora Newton (1686) não fizesse referência direta a vetores, a idéia da força como grandeza vetorial já estava implícita: a Figura 1 mostra que se um corpo fosse levado de A para C pela ação de 
uma força $\mathrm{M}$, ao mesmo tempo em que fosse de A para $\mathrm{B}$ pela força $\mathrm{N}$, então a trajetória do corpo seria na direção $\mathrm{AD}$, o que é chamado de "lei dos paralelogramos". Embora pareça muito simples, este conceito é fundamental para se entender os

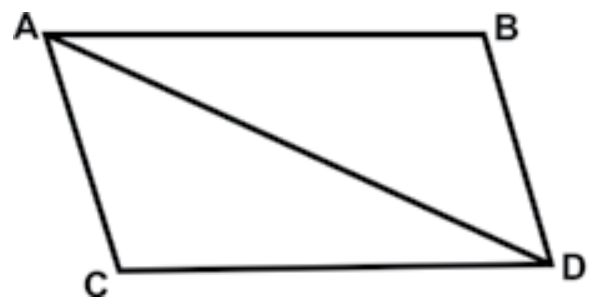

Figura1. Ilustração da Lei dos Paralelogramos (Newton 1686), que forneceu as bases conceituais para o tratamento das forças como grandezas vetoriais

processos que atuam sobre um corpo rochoso quando submetido a uma força qualquer.

Nos dias atuais, o termo "força" é utilizado de duas formas diferentes: no sentido de força mecânica - uma medida exata de interação entre corpos - e, mais frequentemente, como a simples presença de uma interação (Grigoryev \& Myakishev 1967), sendo este último significado muito diferente daquele dado pela mecânica newtoniana. Considera-se que há quatro forças fundamentais no universo: força da gravidade, força eletromagnética, forças nucleares e forças de interação fracas (Grigoryev \& Myakishev 1967).

No interior da Terra as forças são provenientes, em parte, da gravidade atuando sobre cada elemento das rochas, mantendo a coesão da litosfera. Como será visto mais adiante, a força gravitacional atua diretamente nas mudanças de volume dos corpos rochosos - a deformação isotrópica - uma vez que ela atua igualmente sobre cada ponto do corpo.

Deformações anisotrópicas, as quais resultam nas principais estruturas geológicas - falhas, dobras, foliação, etc. - são produto da movimentação das placas tectônicas. Atualmente, o modelo mais aceito associa o movimento dos blocos litosféricos à convecção do calor que, por sua vez, estaria sendo produzido desde a formação da Terra a partir de outra força fundamental, a força nuclear. O deslocamento relativo entre as placas produz uma força de resistência. Este tipo de força, chamado de força de fricção, faz parte, por sua vez, do grupo das forças eletromagnéticas (Grigoryev \& Myakishev 1967). Esta mesma força
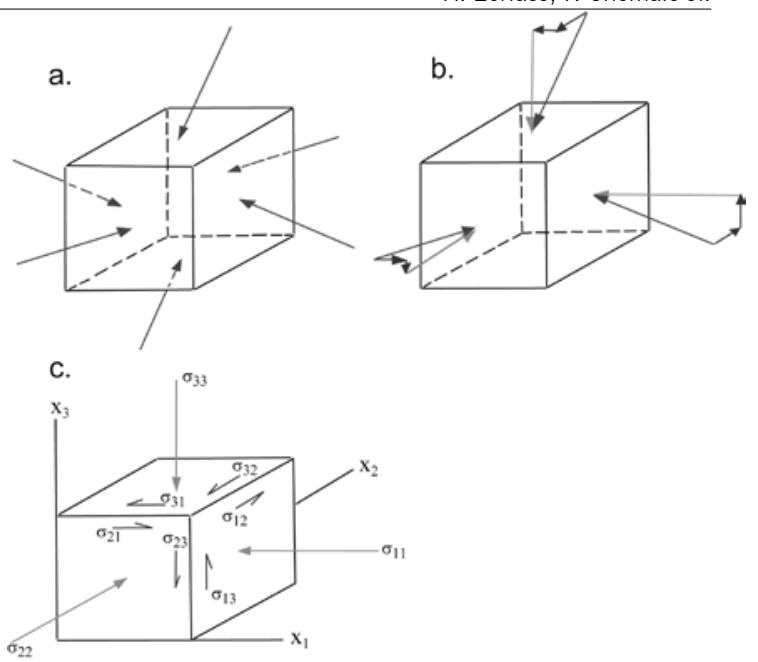

Figura 2. Análise das tensões sobre um cubo de material sólido (Modif. Hobbs et al. 1976). (a) Tensões que atuam sobre as faces do cubo. (b) Decomposição das pressões em componentes ortogonais e paralelos às faces do cubo. (c) Associação dos componentes ao sistema cartesiano de coordenadas $\left(\mathrm{x}_{1}, \mathrm{x}_{2}, \mathrm{x}_{3}\right)$

atuará sempre que houver movimento relativo entre blocos rochosos internos às placas, até a uma escala microscópica, sendo a responsável pela geração das estruturas geológicas.

Um tratamento do conceito de força com significado geológico foi dado por Belousov (1974), considerando que as forças podem ser de volume ou de superfície. As forças de volume são aplicadas diretamente a cada partícula do corpo, como no caso da gravidade, e as forças de superfície atuam na área superficial do corpo (Belousov 1974). Embora este autor tenha chamado esta grandeza de "força", pode-se extrair outro conceito, o da força por unidade de área, ou simplesmente tensão ${ }^{1}$. A tensão pode ser formulada como

$$
T=F / A
$$

onde $F$ é a força aplicada e $A$ a área de aplicação da força na superfície de um corpo. Esta grandeza tem importância fundamental para a geologia estrutural, pois sua magnitude, sua direção e seu sentido são fatores condicionantes da deformação das rochas.

Assim como a força, a tensão também é uma Embora a razão entre força e área seja em geral definida como 'pressão', este termo é usualmente aplicado apenas à tensão hidrostática, que por sua vez define a aplicação de uma força de maneira igualitária sobre toda a superfície de um corpo tridimensional. Dessa forma 0 termo 'tensão' se refere à tensão não-hidrostática. Na literatura em língua inglesa, também existe esta diferenciação semântica, com pressure significando a tensão hidrostática e stress, a tensão não-hidrostática. 
grandeza vetorial. O estudo da atuação da tensão sobre corpos é realizado de forma analítica, decompondo-se cada vetor inicial em mais vetores, com orientações normais ou paralelas a um dado plano. A Figura 2 mostra a análise das tensões que atuam sobre um cubo ideal de material sólido, de acordo com Hobbs et al. (1976). As tensões que atuam sobre as faces de um cubo (Fig. 2a) podem ser decompostas em três componentes ortogonais, um normal e dois paralelos à face do cubo (Fig. 2b). Considerando-se as arestas do cubo como eixos de um sistema de coordenadas cartesianas $\left(\mathrm{x}_{1}, \mathrm{x}_{2}, \mathrm{x}_{3}\right)$ e denominando-se cada componente como $\sigma_{i j}(i$ e $j$ variando de 1 a 3 , por serem três os eixos), o sistema pode ser representado como na figura 2c. Os componentes que apresentam $i=1$ atuam na face normal a $\mathrm{x}_{1}$, e assim por diante. Os componentes que apresentam $i=j$ são chamados de tensões normais, enquanto aqueles que apresentam $i \neq j$ são as tensões cisalhantes. Dessa forma, as tensões atuantes no cubo são decompostas em nove componentes, três normais e seis cisalhantes.

No entanto, um cubo unitário de um corpo sólido está em equilíbro (Loczy \& Ladeira 1976, Price \& Cosgrove 1990). Em outras palavras, as tensões cisalhantes, que poderiam criar um movimento de torção resultante no cubo, tendem a se contrabalançar (Hobbs et al. 1976). Dessa forma, os dois tensores cisalhantes paralelos à mesma face do cubo - os pares $\sigma_{21}-\sigma_{12}, \sigma_{13}-\sigma_{31}$ e $\sigma_{23}-\sigma_{32}$ na Fig. $2 c-$ se subtraem, restando apenas três. Juntando-se estes com os tensores normais, serão apenas seis os componentes independentes que descrevem o estado de tensão de um corpo unitário, três normais e três cisalhantes, simbolizados respectivamente como $\sigma$ e $T$.

Ainda considerando-se o cubo material, há nele três planos em que as tensões cisalhantes são iguais a zero, nos quais o campo de tensões é descrito apenas em termos de tensões normais. Estes são chamados de planos principais de tensão e contém os tensores principais máximo $\left(\sigma_{1}\right)$, intermediário $\left(\sigma_{2}\right)$ e mínimo $\left(\sigma_{3}\right)$ (Hobbs et al 1976, Ramsay \& Huber 1987).

Quando uma rocha é submetida à tensão, suas partículas sofrem deslocamento (Hobbs et al. 1976, Price \& Cosgrove 1990). O deslocamento é dividido em quatro categorias, (1) translação de corpo rígido, (2) rotação de corpo rígido, (3) mudança de volume e (4) distorção (Price \& Cosgrove 1990, Fig. 3).

A translação e a rotação puras dizem respeito
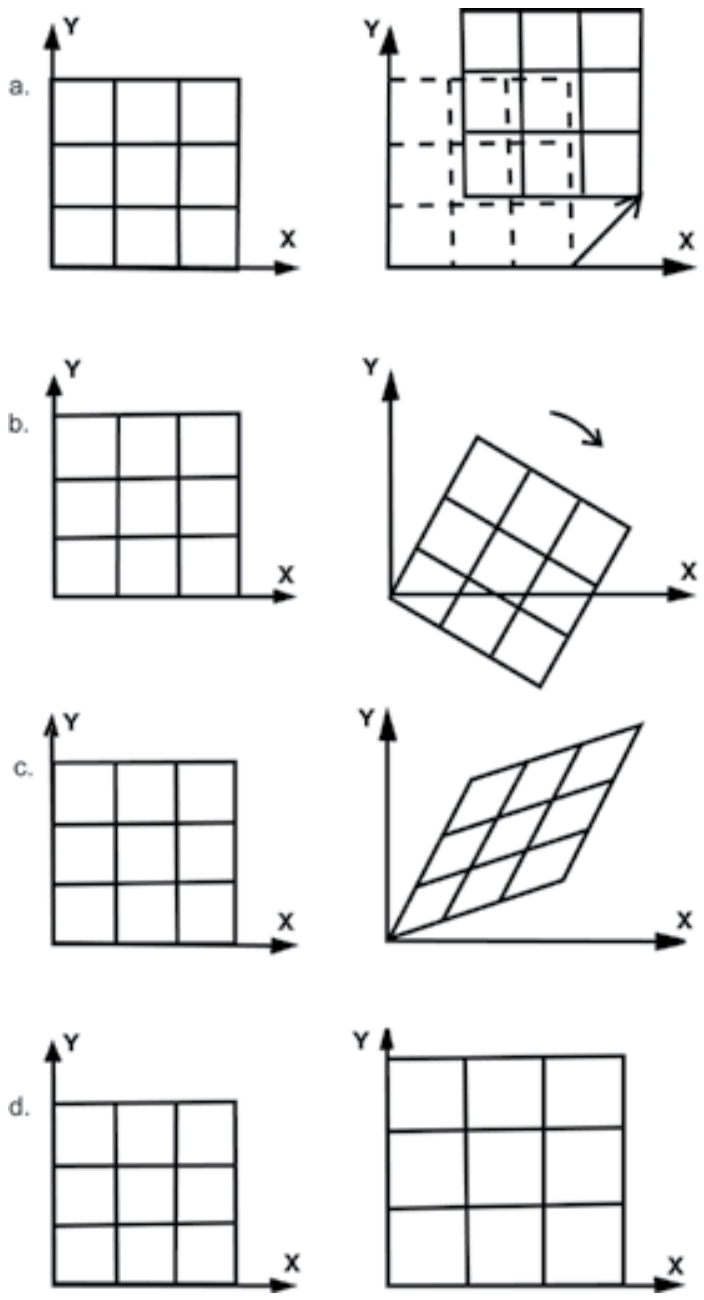

Figura 3. Tipos de deslocamento sofrido pelas partículas de um corpo sólido. (a) Translação de corpo rígido, (b) rotação de corpo rígido, (c) distorção, (d) mudança de volume (Modif. Price \& Cosgrove 1990).

a corpos isolados, não ocorrendo no interior da litosfera. A mudança de volume já foi comentada anteriormente quando se tratou da força da gravidade gerando deformação isotrópica. Do ponto de vista da análise de tensões, isto ocorre quando $\sigma_{1}=\sigma_{2}=\sigma_{3}$ e a tensão é chamada de hidrostática, ou simplesmente pressão. Muitas vezes na literatura há referências à "tensão litostática", o que tem o mesmo significado físico, apenas querendo descrever que o meio é rochoso.

A distorção é o tipo de deformação que produz as estruturas geológicas, e ocorre sempre que o campo de tensão for anisótropo. O grau de anisotropia pode ser avaliado sabendo-se o quanto cada vetor principal se desvia da tensão média ${ }^{2}$, definida como

2 A tensão média, também chamada de tensão confinante, é 0 componente hidrostático em um campo de tensões, no qual também está incluída a pressão de poro. 


$$
\sigma_{m}=\left(\sigma_{1}+\sigma_{2}+\sigma_{3}\right) / 3
$$

Este desvio é dado pela tensão desviante, definida como

$$
\sigma_{d}=\sigma_{N}-\sigma_{m}
$$

sendo $\sigma_{N}$ a tensão normal $\left(\sigma_{1}, \sigma_{2}, \sigma_{3}\right)$. Outra medida usual da capacidade de um campo de tensões de causar deformação é a tensão diferencial,

$$
\sigma_{d i f}=\sigma_{1-} \sigma_{3}
$$

Diz-se que um corpo sob tensão sofre cisalhamento, o qual pode ser de dois tipos. No cisalhamento puro, o corpo é submetido a compressão ou tração em um único sentido. Já no cisalhamento simples, o corpo passa por um deslocamento lateral em dois sentidos diferentes. Isto ficará mais claro no próximo item, quando serão discutidos os ensaios de cisalhamento.

A deformação de sólidos pode ser elástica, quando o corpo retorna à sua forma original ao cessar a aplicação da tensão, ou plástica, quando o corpo mantém a deformação mesmo com o arrefecimento da tensão. Segundo Belousov (1974), a deformação elástica deve-se à ação de forças contrárias à força aplicada em cada ponto do corpo. Estas forças são de origem eletromagnética, e consistem na repulsão ou atração entre as moléculas a fim de se reestabelecer a distância que existe entre elas no corpo em equilíbrio (Grigoryev \& Myakishev 1967). Os corpos com comportamento elástico tendem à homogeneidade e a uma relação linear entre tensão e magnitude de deformação ${ }^{3}$ (Price \& Cosgrove 1990).

Aumentando-se as tensões acima de um valor crítico $\left(\sigma^{c}\right)$, os corpos passam de um comportamento elástico para um comportamento plástico, deformando-se então de forma permanente (Belousov 1974, Hobbs et al. 1976).

Em situações de baixa temperatura e baixa tensão hidrostática, as rochas se deformam desenvolvendo descontinuidades, as quais consistem em quebras de coesão, como as juntas e as falhas (Hobbs et al. 1976), o que é comumente referido como deformação rúptil. Segundo Mandl (1988), na deformação rúptil não há uma correlação entre tensão e magnitude de deformação; um grão se

3 A magnitude de deformação - strain na literatura em inglês - é um parâmetro geométrico. Uma forma simples de desenvolver este conceito é imaginar uma esfera contida em um corpo sólido não deformado e que, devido à deformação, será transformada em um elipsóide sempre que 0 campo de tensões for anisótropo. Quanto maior a disparidade geométrica entre a esfera e o elipsóide resultante, maior a magnitude de deformação.

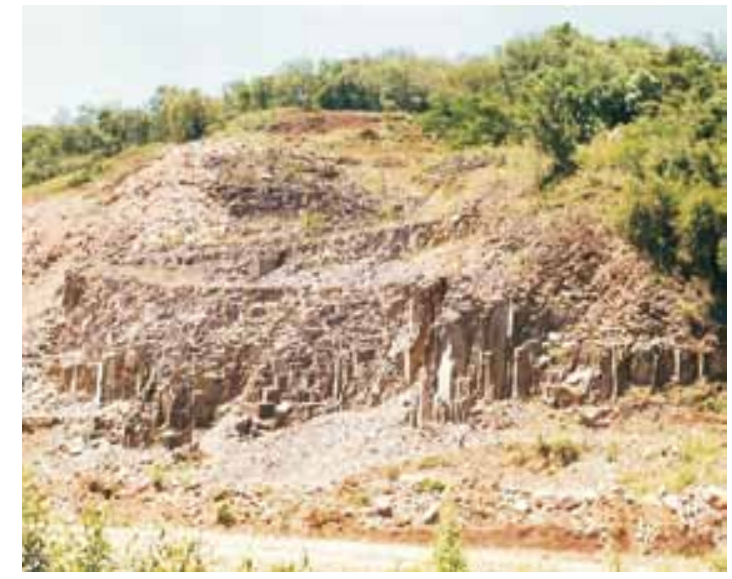

Figura 4. Juntas (diáclases) provocadas por resfriamento e contração de rocha vulcânica - disjunções colunares (Formação Serra Geral, Cretáceo Inferior, São Pedro do Sul, RS).

parte ou desliza friccionando seus vizinhos, ou uma microfratura cresce quando a tensão local chega a um ponto crítico, mas a taxa em que este microprocesso evolui é praticamente independente da tensão local.

Com o aumento da tensão hidrostática e da temperatura, as rochas tendem a se deformar de maneira mais uniforme, o que consiste no comportamento dúctil ou viscoso (Hobbs et al. 1976). Neste caso, a magnitude de deformação aumenta de forma diretamente proporcional à tensão aplicada (Mandl 1988).

Neste artigo são abordadas as estruturas geradas em ambiente rúptil, as quais serão definidas a seguir, para uniformização da linguagem a ser utilizada, porque há diferentes definições na bibliografia, e alguns termos podem se tornar ambíguos.

\section{Estruturas rúpteis}

\subsection{Juntas}

Juntas são estruturas planares geradas por abertura, sem cisalhamento, nas quais a deformação atua no sentido de afastamento das paredes (Fig. 4).

\subsection{Falhas}

Falhas são estruturas planares em que se pode observar movimento relativo entre os blocos, paralelo ao plano da estrutura (Fig. 5). Ao contrário de alguns autores, não se leva em consideração aqui a medida linear absoluta do deslocamento; considera-se mais importante a verificação obje- 


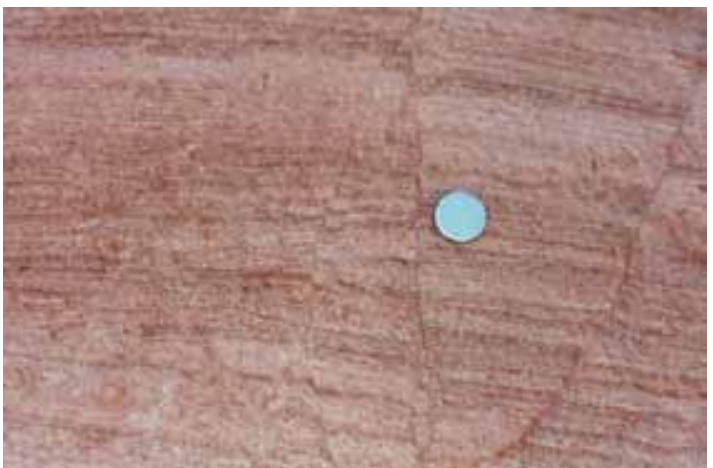

Figura 5. Falha com rejeito milimétrico observado no deslocamento das lâminas de arenito (Formação Pirambóia, Permiano Superior, Dilermando Aguiar, RS. A moeda mede $2,2 \mathrm{~cm}$ de diâmetro.

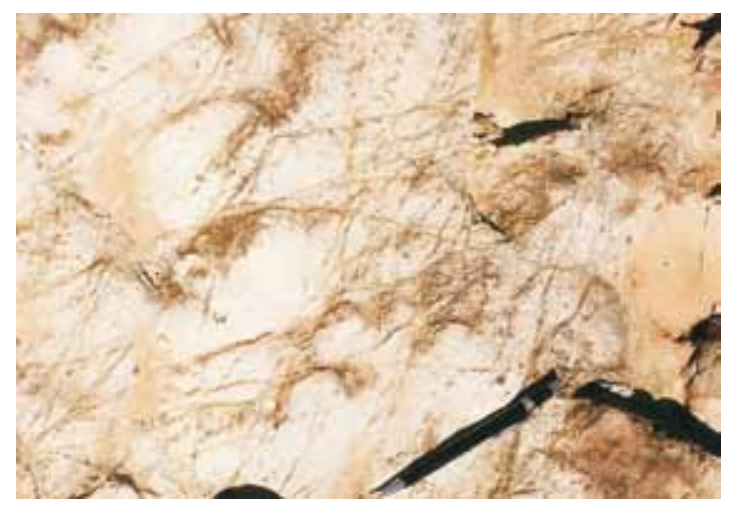

Figura 6. Fraturas, sem evidência direta de cisalhamento ou abertura (Formação Santa Maria, Triássico Médio, São Pedro do Sul, RS).

tiva da existência de deslocamento paralelo ao plano da estrutura, independentemente da escala de observação. Também não é feita distinção entre falhas naturais e produzidas em laboratório, estas últimas chamadas de "fraturas de cisalhamento" por alguns autores.

\subsection{Fraturas}

O termo "fratura", embora seja o mais comumente empregado em trabalhos sobre estruturas rúpteis, é também o mais vago. Apesar disso, sua utilização é praticamente inevitável na prática, como termo genérico para as estruturas planares disruptivas de um modo geral. E, de um modo particular, sugere-se também sua utilização quando uma determinada estrutura não revela evidências, na escala de observação, do tipo de movimento relativo entre os blocos, se cisalhamento ou abertura (Fig. 6).

\section{Início de fraturas}

Um geólogo, ao observar lineamentos em uma imagem de satélite ou fraturas em um afloramento, está estudando feições que se formaram, na maioria dos casos, pela reativação de estruturas mais antigas, bem como pela coalescência de segmentos menores. A base conceitual da mecânica, que considera os modelos idealizados, é muito importante, pois permite que se conheça s processos atuantes na deformação das rochas, e seus produtos. No entanto há limitações para sua aplicação em Geologia. O que se observa na realidade geológica é um conjunto de estruturas que representa o momento final de um complexo processo evolutivo na escala do tempo geológico, em que há o contínuo incremento nas deformações, conforme discutido por Ramsay \& Huber (1987). Estes autores ainda alertam para o cuidado que se deve ter em não confundir a dinâmica instantânea do sistema em um momento dado e o estado final de deformação, que é conhecido pela geometria geral. Em outras palavras, ao contrário dos ensaios de laboratório, onde são conhecidos os estados de tensões, em Geologia os dados são os deslocamentos e deformações.

A abordagem mecânica deve ser feita, portanto, de uma forma relativa, permitindo que se relacione as geometria com prováveis processos formadores. Há duas abordagens distintas em termos de escala. $\mathrm{Na}$ abordagem macroscópica, analisa-se o estado de tensão de um corpo rochoso quando do fraturamento. Este assunto foi desenvolvido em grande parte pelo estudo das deformações em corpos de prova durante ensaios de tensão.

$\mathrm{Na}$ abordagem microscópica, por sua vez, estuda-se o desenvolvimento das microfissuras que dão origem às fraturas macroscópicas, em especial a relação entre o campo de tensões local e a textura da rocha. Modelos teóricos nesse caso assumem um papel preponderante.

\subsection{Visão macroscópica}

O conhecimento sobre os processos envolvidos para iniciar uma fratura qualquer, sob o ponto de vista macroscópico, foi construído associando-se a mecânica teórica com ensaios de cisalhamento. Por intermédio desse tipo de ensaio, uma amostra de rocha ou solo é submetida a tensões controladas, conhecendo-se assim o estado de tensão no momento da ruptura. 


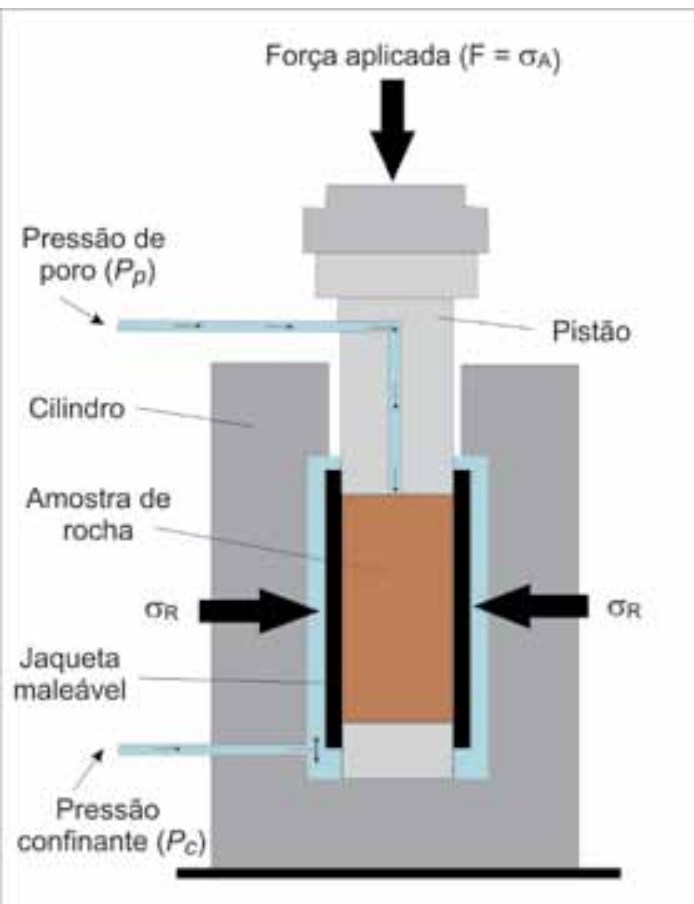

Figura 7. Esquema de um equipamento de ensaio triaxial (Modif. Pollard \& Fletcher 2005)

No caso das rochas, o ensaio mais comum é o de cisalhamento puro, com um sistema triaxial de tensões. Apesar do nome, este ensaio não é capaz de aplicar tensões normais segundo três eixos, mas uma tensão axial e outra radial, o que se aproxima de um sistema de tensões real na crosta terrestre. Pollard \& Fletcher (2005) apresentam em detalhe o funcionamento da ferramenta esquematizada na Figura 7. Em linhas gerais, um pistão aplica uma tensão axial sobre o corpo de prova. A injeção de um fluido no espaço entre a parede interna do cilindro de pressão e uma jaqueta de material impermeável e maleável que envolve a amostra - borracha, cobre, etc. - gera uma pressão confinante $\left(\mathrm{P}_{c}\right)$. Através de outra entrada é injetado fluido diretamente na superfície da amostra produzindo uma pressão de poro $\left(\mathrm{P}_{\mathrm{p}}\right)$. Como $\mathrm{P}_{\mathrm{p}}<\mathrm{P}_{c}$, tem-se uma tensão radial, sistema que permite um estado de tensões uniforme em todo o corpo de prova. A tensão axial gerada pelo pistão $\left(\sigma_{A}\right)$ é diretamente relacionada à força aplicada $(\mathrm{F})$ e à área da seção do corpo de prova (A), de modo que

$$
\sigma_{A}=-F / A=\sigma_{1} \text { ou } \sigma_{3}
$$

A tensão radial $\left(\sigma_{\mathrm{R}}\right)$ corresponde à pressão confinante, ou seja,

$$
\sigma_{R}=-P_{c}=\sigma_{2} \text { e } \sigma_{3} \text { ou } \sigma_{1} \text { e } \sigma_{2}
$$

O sinal negativo do segundo termo das equações vem de uma convenção utilizada em mecânica de rochas, segundo a qual os esforços compressivos têm sinal negativo. Esse tipo de ensaio é regulado pela compressão do cilindro, e o balanço de forças definirá o teste como distensional ou compressional. A qual dos três vetores de tensão principais corresponderão $\sigma_{\mathrm{A}}$ e $\sigma_{\mathrm{R}}$ dependerá da relação entre $\mathrm{F}$ e $\mathrm{P}_{c}$. Quando a pressão confinante suplantar a força aplicada pelo pistão, então $\sigma_{\mathrm{R}}>\sigma_{\mathrm{A}}$ e $\sigma_{\mathrm{A}}=\sigma_{3}$, e o teste será distensional. Se a força do pistão for maior do que a pressão confinante, $\sigma_{\mathrm{R}}<\sigma_{\mathrm{A}}$ e $\sigma_{\mathrm{A}}=\sigma_{1}$, e o teste será compressional.

Os princípios teóricos implícitos nestes testes têm história bastante longa. O físico francês Charles Augustin de Coulomb (1736-1806) formulou a teoria de que um material apresenta um valor determinado de tensão cisalhante acima do qual ocorre seu fraturamento, o que é chamado de limite de cisalhamento e que depende da composição do material testado.

Desenvolvendo este postulado, o engenheiro Christian Otto Mohr (1835-1918) mostrou a existência de uma função entre as tensões normal e cisalhante no momento da ruptura, a qual prevê que a tensão cisalhante necessária para o fraturamento terá que ser maior quanto maiores forem as tensões normais. Além disso, Mohr também levou em consideração as propriedades físicas dos materiais, como a coesão e a capacidade de desenvolver atrito interno.

\subsubsection{Diagrama de Mohr}

Para melhor descrever o estado de tensões de um corpo no momento de sua ruptura, Mohr desenvolveu um diagrama cartesiano, denominado de diagrama de Mohr, o qual tem uma grande aplicação prática. Neste diagrama, os eixos de tensões normais $\sigma_{1} \sigma_{2}$ e $\sigma_{3}$ estão posicionados num mesmo eixo (horizontal), e a tensão cisalhante, no eixo vertical. Os valores positivos de tensão normal são associados, por convenção, à extensão, e valores negativos, à compressão. Os valores de tensão cisalhante $(T)$ são considerados em módulo; o fato de serem positivos ou negativos se relaciona com aspectos geométricos, mas há uma relação de simetria que não interfere nas interpretações.

O estado de tensões de um corpo é descrito por um círculo. A partir da observação do gráfico, pode-se extrair os valores das tensões atuantes no momento do fraturamento, bem como as rela- 
a.

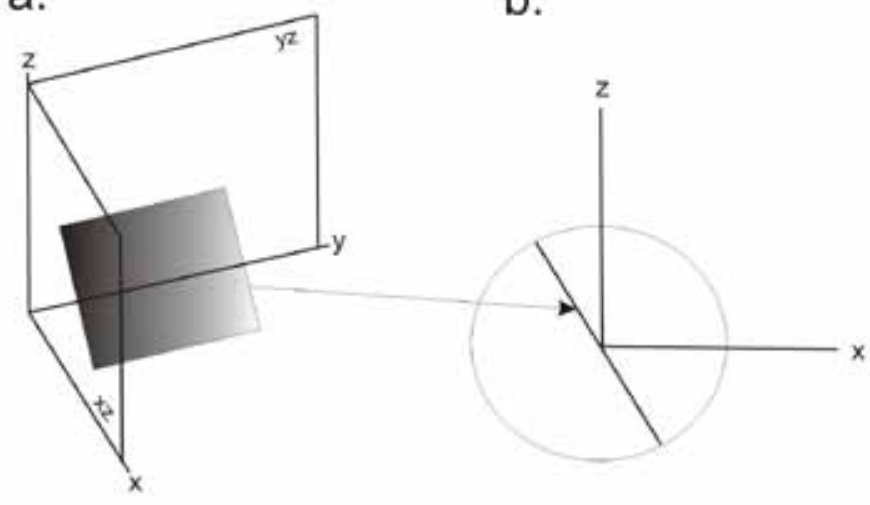

C.

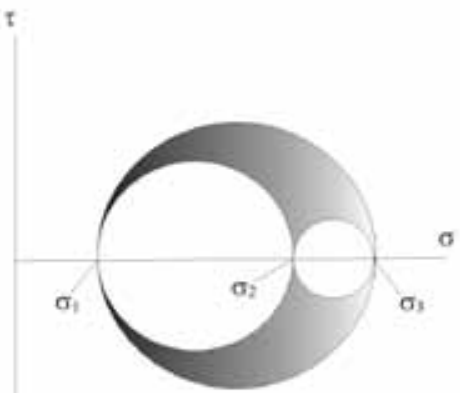

Figura 8. Construção geométrica do Círculo de Mohr (modificada de Davis \& Selvadurai 2002). (a) Sistema tridimensional de coordenadas ( $x, y, z)$ mostrando um plano qualquer paralelo ao eixo y. (b) Vista em perfil do mesmo plano e do círculo gerado pela sua rotação segundo y. (c) Exemplos de círculos gerados pela rotação de planos paralelos a cada um dos eixos $x, y, z$, os quais correspondem, respectivamente, a $\sigma_{1}, \sigma_{2}$ e $\sigma_{3}$. O plano hachurado, paralelo a $\sigma_{2}$, corresponde ao Círculo de Mohr

ções geométricas entre os tensores e as estruturas geradas. Entretanto, a representação de um sistema de tensões tridimensional em um diagrama bidimensional cria algumas dificuldades para seu entendimento. Dessa forma, é importante que se faça uma comparação entre o diagrama de Mohr e o espaço tridimensional.

No espaço $x, y, z$, suponha-se que seja definido um plano $x z$ e outro plano perpendicular $y z$. Ao se rotacionar este último plano são obtidos infinitos planos, paralelos a $\gamma$ (Fig. 8a), cuja projeção forma um círculo sobre o plano $x z$ (Fig. 8b); estes planos pertencem a uma mesma família, pois foram gerados pelo eixo $y$ (Davis \& Selvadurai 2002). Da mesma forma, duas outras famílias de planos poderão ser geradas pela revolução de um plano qualquer segundo os eixos $x$ e $z$, formando círculos quando projetadas sobre o respectivo plano perpendicular, $y z$ para a rotação segundo $x$ e $x y$ para a rotação sobre $z$.

Considerando-se as tensões principais $\sigma_{1}, \sigma_{2}$ e $\sigma_{3}$ como paralelas aos eixos $x, y$ e $z$, respectivamente, as três famílias de planos geradas formam três círculos de tensões, mostrados na Figura 8c. As três famílias de planos possuem sempre um tensor principal nulo, justamente aquele que serviu como eixo de rotação para gerar uma determinada família de planos. Os demais planos possíveis, em que nenhum dos três tensores principais é zero, estão posicionados na área hachurada na Figura 6c. Comumente é mostrado somente o círculo maior, uma vez que os pontos situados sobre o mesmo

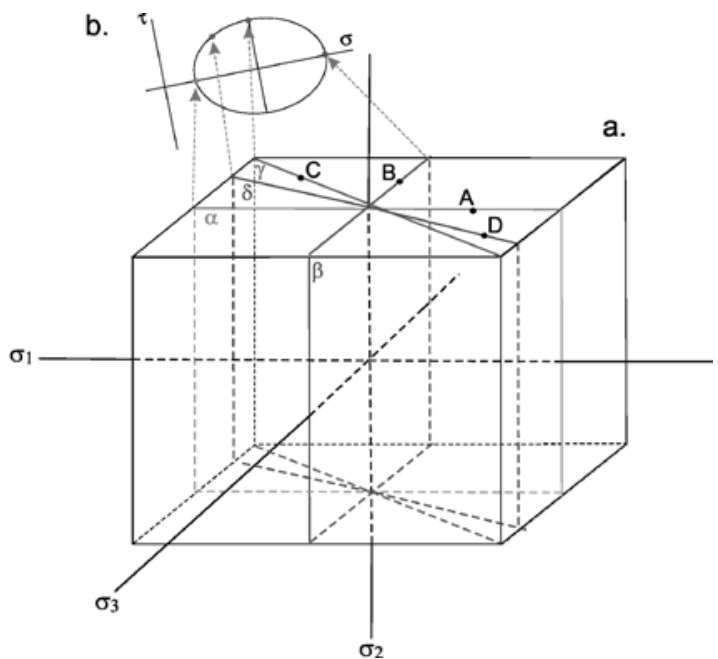

Figura 9. Relação geométrica entre um cubo material (a) e o diagrama de Mohr (b)

descrevem o estado de tensões no limite do fraturamento (Davis \& Selvadurai 2002). Do ponto de vista físico, o diâmetro do círculo maior quantifica a tensão diferencial $\left(\sigma_{1}-\sigma_{3}\right)$.

Para que se visualize melhor a relação do diagrama de Mohr com o espaço tridimensional, é mostrada aqui uma comparação entre um corpo material orientado segundo os eixos de tensões normais (Fig. 9a) e o diagrama de Mohr (Fig. 9b). Neste exemplo, serão abordados apenas os planos da família gerada pela rotação do eixo $\gamma$, aqui substituído por $\sigma_{2}$. Em primeiro lugar, é importante salientar que no exemplo dado os valores de $\sigma_{2}$ são sempre nulos. Isto não significa que esse tensor não exista no sistema, o que não faria sentido conceitualmente, mas que, para a família de planos paralelos 
a.

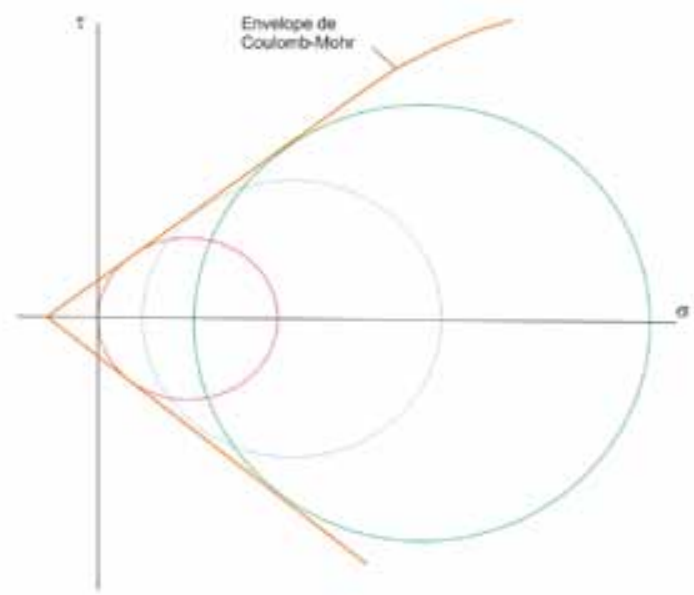

b.

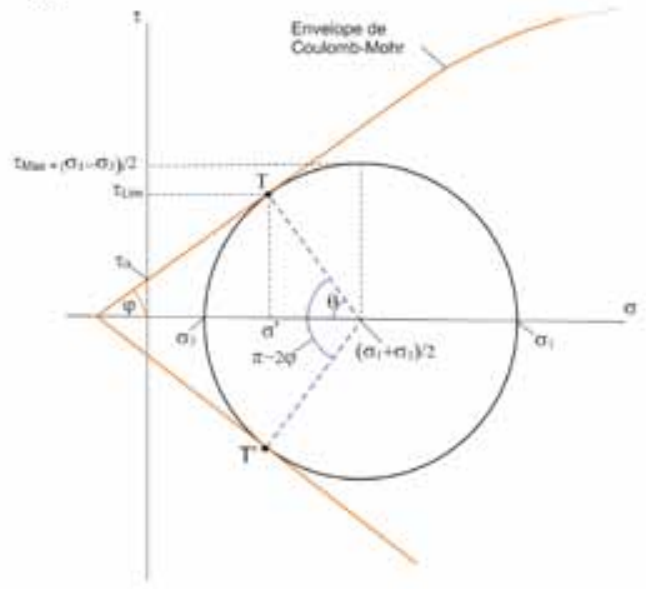

Figura 10. Elementos do diagrama de Mohr. (a) Construção do envelope de Mohr-Coulomb para um material específico. (b) Elementos importantes observáveis no diagrama (modificada de Mandl 1988)

ao eixo $\gamma$, a projeção de $\sigma_{2}$ é nula.

Na Figura 9, o ponto A está contido no plano $\alpha$, no qual a tensão normal $\left(\sigma_{\mathrm{N}}\right)$ atuante é igual a $\sigma_{3}$ e a tensão cisalhante é nula. Da mesma forma, o ponto B está contido no plano $\beta$, no qual $\sigma_{\mathrm{N}}=\sigma_{1} \mathrm{e}$ a tensão cisalhante é igualmente nula. Já o ponto $\mathrm{C}$ está contido no plano $\gamma$, a $45^{\circ}$ dos dois anteriores. Nesta situação, a tensão cisalhante $T$ é máxima indicada como $T_{\mathrm{Max}}$ no eixo vertical do diagrama - e $\sigma_{\mathrm{N}}$ coincide com a tensão média. Planos intermediários, como $\delta$, que contém o ponto $\mathrm{D}$, possuem valores de $\sigma_{\mathrm{N}}$ mais próximos de $\sigma_{1}$ ou $\sigma_{3}$ e valores intermediários de $T$.

Lição importante que pode ser extraída da Figura 9 é que o ângulo de $90^{\circ}$ existente entre os eixos $\sigma_{1}$ e $\sigma_{3}$ no cubo "transforma-se" em um ângulo de $180^{\circ}$ no diagrama de Mohr. Dessa forma deve-se ter em mente que qualquer relação angular observada no diagrama corresponde ao dobro daquela existente na natureza. A construção do diagrama de Mohr a partir do espaço tridimensional é feita matematicamente, o que está além do escopo deste trabalho. Para maiores informações, sugere-se o item específico no Apêndice B do livro de Davis \& Selvadurai (2002).

Abordando-se em mais detalhe o diagrama de Mohr, há nele a representação de diversos elementos que, em conjunto com os tensores, descrevem o comportamento do material próximo ao estágio de ruptura. Uma função importante é chamada de Envelope de Mohr-Coulomb, que define o estado de tensões (cisalhantes e normais) na iminência da ruptura (Fig. 10a,b).
Mohr definiu essa função realizando ensaios triaxiais sistemáticos com o mesmo material. $\mathrm{Na}$ Figura 10a os círculos representam resultados para diferentes corpos de prova, cada um com um estado de tensões distinto. Graficamente, o envelope corresponde à reta que tangencia todos os círculos. De acordo com Mandl (1988), o mesmo é uma função do ângulo $\varphi$ e da tensão confinante efetiva $\left(\sigma^{\prime}\right)$,

$$
|T|=\tau_{0}+\sigma^{\prime} \tan \varphi
$$

O ângulo $\varphi$ (Fig. 10b) é o ângulo de fricção interna, originário da mecânica de solos, uma vez que a fricção interpartículas é o fator primordial de resistência ao cisalhamento; os valores de $\varphi$ variam de $10^{\circ}$, para argilas muito macias, a $35^{\circ}-50^{\circ}$ em areias densas; para rochas duras, os valores são maiores (Mandl 1988).

A tensão confinante efetiva que, por sua vez, representa a tensão média $\left(\sigma_{\mathrm{m}}\right.$ equação 2$)$ subtraída a pressão de poro (Mandl 1988), é representada como

$$
\sigma^{\prime}=\left(\sigma_{1}+\sigma_{2}+\sigma_{3}\right) / 3-P_{P}
$$

O termo $T_{0}$ (Fig. 10b) é a resistência coesiva ao cisalhamento $^{4}$, que representa o valor crítico para cada material a partir do qual é possível a deformação plástica, e que se manterá constante durante todo o evento deformacional. O significado físico de $T_{0}$ se traduz na sua ação no sentido de quebrar a resistência ao fraturamento, a qual é dada pela tensão confinante efetiva $\left(\sigma^{\prime}\right)$ (Mandl 1988). A resistência coesiva ao cisalhamento pode ser vista como o componente de tensão cisalhante necessário para 4 Tradução livre para coesive shear strenght. 

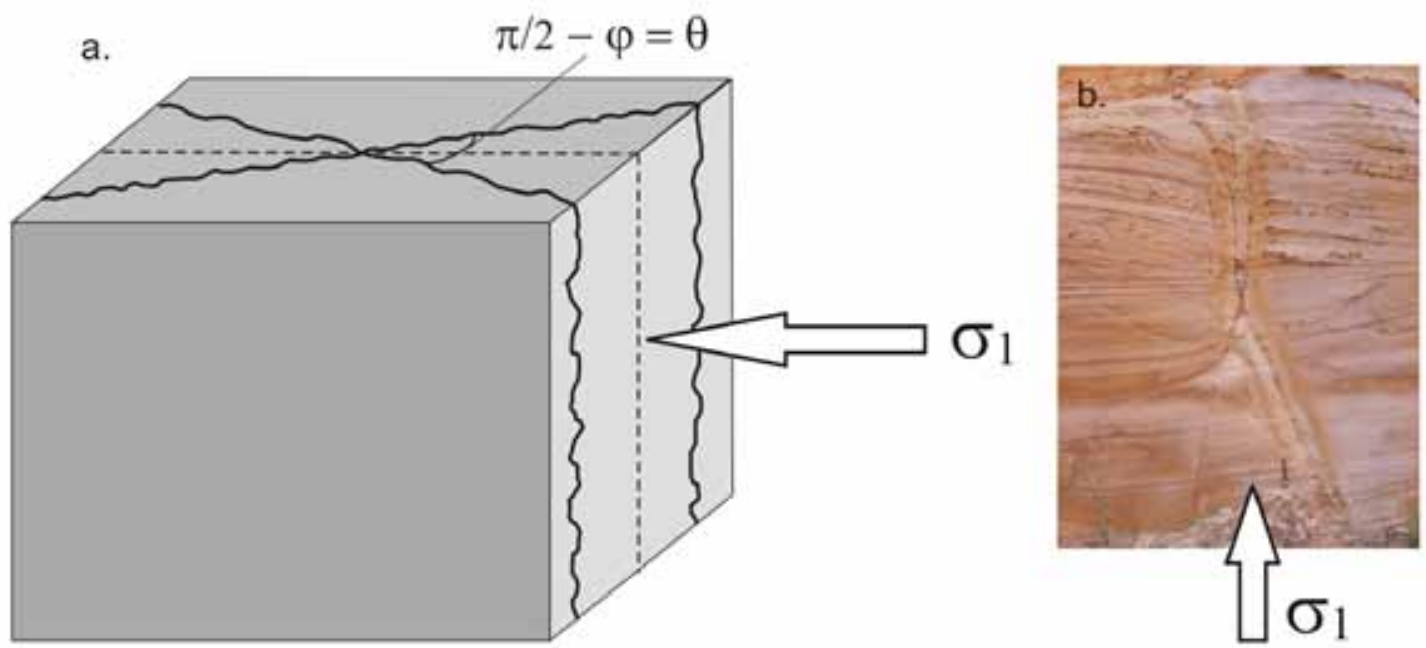

Figura 11. (a) Relação geométrica tridimensional entre um par conjugado de fraturas formado sob um determinado estado de tensões e o eixo principal de tensão $\left(\sigma_{1}\right)$. (b) Exemplo natural de par conjugado em arenito (Formação Mangabeira, Mesoproterozóico, Seabra, BA)

que haja a mínima possibilidade de ruptura.

Como a relação expressa em (7) tem que ser mantida para cada material, então o círculo de tensões só poderá tangenciar o envelope, o que ocorre nos pontos T e T’ (Fig. 10b). A projeção de $\mathrm{T}$ e $\mathrm{T}^{\prime}$ sobre o eixo $\sigma$ corresponde ao valor da tensão confinante efetiva no estado limite de fraturamento $\left(\sigma^{\prime}\right)$, e a projeção sobre o eixo $T$ indica a tensão cisalhante no ponto de ruptura $\left(\tau_{\text {Lim }}\right)$ (Fig. 10b). A tensão cisalhante será máxima $\left(T_{\mathrm{Max}}\right)$, nos planos situados a $45^{\circ}$ de $\sigma_{1}$ e $\sigma_{3}$, na mesma situação do plano $V$ na Figura 9. O valor de $T_{\text {Max }}$ corresponde ao raio do círculo $\left(\sigma_{1}-\sigma_{3}\right) / 2$ (Fig. 10b) (Mandl 1988).

No diagrama de Mohr o ângulo formado entre os raios que contêm $\mathrm{T}$ e $\mathrm{T}^{\prime}$ corresponde a $180^{\circ}$ $2 \varphi$ (Fig. 10b). Este ângulo é importante porque a partir dele será possível conhecer-se o ângulo que as fraturas formadas mantêm com o eixo $\sigma_{1}$, uma das principais propriedades do diagrama. Neste momento, esta questão é de mais fácil compreensão ao se voltar ao cubo material (Fig. 11). Como visto anteriormente, no cubo tridimensional quaisquer ângulos correspondem à metade de sua representação no diagrama. Assim, na Figura 9a, os planos que contêm $\mathrm{T}$ e $\mathrm{T}^{\prime}$, que são planos de fraturas conjugadas, mantêm entre si um ângulo de $90^{\circ}-\varphi$, comumente chamado de $\theta$; sua bissetriz indica a posição de $\sigma_{1}$. Voltando-se ao diagrama de Mohr, $\theta$ será representado como o ângulo formado entre o raio contendo $\mathrm{T}$ ou $\mathrm{T}^{\prime}$ e o eixo $\sigma$ (Fig. 10b).

Segundo Mandl (1988), em materiais isótropos o ângulo $\theta$ não terá preferência quanto ao sinal, e duas falhas conjugadas vão se formar desde que a orientação dos eixos de tensão não varie, o que privilegiaria o desenvolvimento de um plano em relação ao outro. Isto permite que se conheça, pelas relações geométricas, se dois planos podem ou não ser conjugados, o que significa terem se formado no mesmo evento deformacional. Esta questão é muito importante quando se busca estabelecer a sequência de eventos em uma área.

Os pares conjugados de fraturas são feições que podem ser observadas em afloramento. Como ambos os planos evoluem conjuntamente, sua geometria é em " $X$ ". Na zona de intersecção entre os planos desenvolve-se uma zona altamente deformada para acomodar a movimentação sincrônica dos mesmos (Fig. 11b).

\subsection{Visão microscópica}

Uma vez conhecido o estado de tensões de uma rocha no momento de seu fraturamento, outra questão que surge é a de como e a partir de que ponto no interior de uma rocha não deformada o processo de fraturamento é desencadeado. Esta não é uma pergunta nova e três trabalhos foram fundamentais para o desenvolvimento deste conhecimento.

Charles Edward Inglis (1875-1952) publicou em 1913 um dos mais citados artigos sobre mecânica de fraturas, curiosamente aplicado ao problema da resistência dos cascos de navios (Pollard 


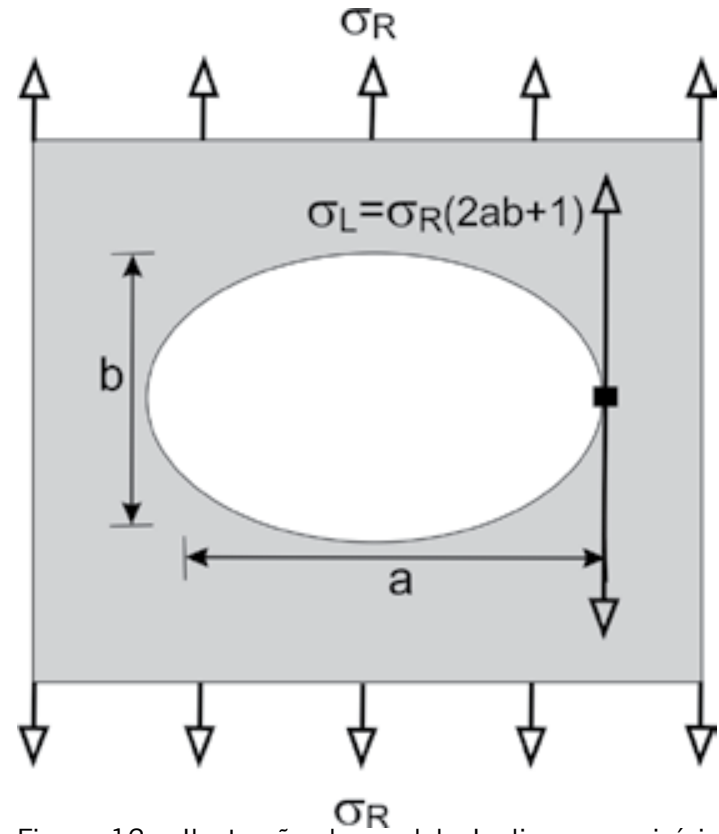

Figura 12. Ilustração do modelo Inglis para o início de uma fratura a partir de uma cavidade elíptica (Modif. Pollard \& Fletcher 2005)

\& Fletcher 2005). Ele propôs que fraturas teriam sua propagação iniciada nas bordas de cavidades e tratou matematicamente o problema. Utilizando a situação hipotética em que uma cavidade elíptica, com um eixo maior $a$ e um eixo menor $b$, é observada em uma seção de um corpo material com área infinita, disposta de modo que a seja perpendicular à tensão remota (Fig. 12), Inglis demonstrou que a tensão é amplificada na extremidade da cavidade, de acordo com a relação

$$
\sigma_{L}=\sigma_{R}(2 a b+1)
$$

na qual $\sigma_{\mathrm{L}}$ é a tensão localizada na extremidade da cavidade e $\sigma_{\mathrm{R}}$ é a tensão remota em toda a seção (Pollard \& Fletcher 2005). Assim, quanto mais alongada for a elipse - exatamente o caso de uma microfratura na rocha ou um defeito na estrutura cristalina de um grão mineral - maior será o fator de multiplicação da tensão remota na extremidade da cavidade. Esse acréscimo substancial na extremidade de uma fissura pode gerar um estado de tensões que suplanta a resistência coesiva ao cisalhamento, gerando a ruptura. Apesar do grande avanço sobre as abordagens anteriores, que fez com que Inglis seja considerado o pai da mecânica de fraturas, sua abordagem não resolve de forma satisfatória o problema da definição do campo de tensões na extremidade de fissuras planares, em que $b$ é irrelevante (Pollard \& Fletcher 2005).
Na década de 1920, Alan Arnold Griffith (18931963), trabalhando em laboratório especialmente com vidro, associou a origem de fraturas a descontinuidades microscópicas das rochas (Ramsay \& Huber 1987, Pollard \& Fletcher 2005). Griffith sugeriu que, quando um conjunto de fissuras fosse submetido a tensão, tensões locais muito altas seriam desenvolvidas, principalmente nas extremidades das fissuras, conduzindo à propagação de fissuras microscópicas, a interconexões entre fissuras e, finalmente, ao desenvolvimento de fraturas descontínuas (Ramsay \& Huber 1987). Uma importante contribuição de Griffith foi associar a ruptura de um corpo às microfissuras inerentes a qualquer material, rochoso ou não; as microfissuras ocorrem em diferentes orientações e aquelas mais próximas da perpendicular a $\sigma_{3}$ serão as mais propensas a dar início à ruptura no caso de um campo de tensões distensional.

Um problema com a abordagem de Griffith, apontado por Engelder (1994), seria o da insuficiente definição do campo de tensões nas adjacências das extremidades das fissuras. Partindo desta questão, George Rankine Irwin (1907-1998) sugeriu que o campo de tensões nas vizinhanças das extremidades de uma fissura seria proporcional ao fator de intensidade de tensão $(K)$, definido como

$$
K=\lim \left[\sigma_{N}(2 \pi R)^{1 / 2}\right]
$$

onde $\sigma_{\mathrm{N}}$ é a tensão normal ao plano da fissura e R é a distância em relação à fissura (Irwin 1958, apud Engelder 1994). Quando este fator atinge, na extremidade de uma fissura microscópica, um valor igual ou superior a um valor crítico para cada material $\left(\mathrm{K}_{\mathrm{IC}}\right)$ a fissura irá se propagar a uma velocidade aproximadamente igual à do som (Atkinson \& Meredith 1987, Costin 1987, Pollard \& Fletcher 2005). O valor crítico é chamado de resistência ao fraturamento ${ }^{5}$, o qual depende de fatores como temperatura, tensão confinante e ambiente geoquímico (Pollard \& Fletcher 2005).

As fraturas também podem se formar a partir de inclusões como fósseis, grãos e outros objetos, desde que estes tenham propriedades elásticas diferentes da rocha encaixante (Pollard \& Aydin 1988). Conforme a relação dos módulos de cisalhamento $(\mu)^{6} \mathrm{da}$ encaixante e da inclusão, é possível formarem-se juntas sob um campo de tensões remotas distensional e até mesmo compressional (Pollard \& Aydin 1988).

5 Tradução livre de "fracture toughness".

6 Constante elástica que depende do material, a qual é uma função da tensão cisalhante, da deformação e de aspectos geométricos (Andrade, 2003). 


\section{Propagação e ligação de fraturas}

Como regra geral, uma microfissura irá se propagar quando o fator de intensidade de tensão (K, equação 10) atingir um valor crítico na extremidade da mesma. Algumas particularidades, no entanto, envolvem os processos de propagação e ligação das juntas, por um lado, e das falhas, por outro.

\subsection{Juntas}

Uma junta tende a se propagar em uma direção normal à principal direção de extensão $\left(\sigma_{3}\right)$. A própria junta, ao se propagar, modifica o campo de tensão em intensidade e direção (Ingraffea 1987). Apesar disso, muitas juntas naturais não são superfícies planas, o que sugere que a propagação se desvia da direção preferencial; isto ocorre quando há torção e rotação pela superposição de tensão cisalhante paralela à propagação (Engelder 1987).

As juntas ocorrem como conjuntos uniformemente espaçados, que podem ser correlacionados por centenas de quilômetros de distância, ou apresentam espaçamento mais irregular (Engelder 1987). O espaçamento e a densidade das juntas podem ser influenciados pela espessura da camada que as contém, por mudanças litológicas, pela distância do ponto de início e pela velocidade de resfriamento, sendo este último fator importante para rochas vulcânicas (Pollard \& Aydin 1988). O número de juntas decresce quanto maior for a distância do ponto de início, e o espaçamento diminui com o aumento da velocidade de resfriamento (Pollard \& Aydin 1988).

De modo geral, as juntas se formam quando a rocha está submetida à distensão ou quando a rocha se contrai, por resfriamento ou perda de fluido. No caso de distensão, enquanto o campo de tensão permanecer inalterado, as juntas serão paralelas entre si. Hancock (1985) define este sistema como de geometria $\mathrm{em} \mathrm{I}^{7}$. Esta simetria atesta que as juntas se formaram a partir de microfissuras perpendiculares à extensão remota $\left(\sigma_{3}\right)$, onde o máximo fator de intensidade de tensão $(\mathrm{K})$ se desenvolveu em suas extremidades, resultando em uma propagação de fraturas muito uniforme. No segundo caso, a contração da rocha, por ser em todas as direções, produz sistemas poligonais, em especial os hexagonais. Estes são os que se aproximam mais de uma

7 Hancock (1985) discute a origem e evolução de sistemas de juntas a partir de uma classificação geométrica muito útil, em especial no campo. A classificação se baseia na semelhança das relações geométricas dos sistemas de juntas com letras do alfabeto: I, K, X, T, Y. seção circular que representaria uma contração perfeita. De acordo com Hancock (1985), este tipo de juntas se forma em um campo de tensão aproximadamente hidrostático $\left(\sigma_{1} \approx \sigma_{2} \approx \sigma_{3}\right)$ e apresenta geometria em K. Um exemplo desse tipo de juntas são as disjunções colunares, formadas pelo resfriamento de rochas vulcânicas (Fig. 4).

Price (1966, apud Ramsay \& Huber 1987) postulou que as juntas seriam preferencialmente geradas durante o soerguimento de uma área, como resultado da recuperação da deformação elástica armazenada; neste caso, a geometria do sistema teria relação com as estruturas previamente formadas. Assim, esse processo também deve ser levado em consideração, sendo importante um conhecimento prévio da história geológica da área.

\subsection{Falhas}

As falhas, por sua vez, podem ter sua propagação iniciada a partir de juntas pré-existentes (Engelder 1987, Willemse et al. 1997, Mansfield \& Cartwright 2001) ou de fissuras microscópicas quaisquer, reativadas por deslizamento sob tensão cisalhante (Engelder 1987). Martel et al. (1988) e Martel (1990) ainda propõem que as falhas possam se desenvolver a partir de juntas iniciadas sob compressão, paralelas ao eixo principal de tensão.

De acordo com Engelder (1987), para que ocorra o início e a propagação de falhas a tensão diferencial deve ser mais alta do que as diferenças das tensões regionais médias no interior da crosta, o que é atestado por ensaios de laboratório. Isto faz com que uma falha se inicie em regiões localizadas.

O conhecimento sobre a formação e ligação de falhas foi em grande parte construído por meio dos chamados testes de cisalhamento simples. Os trabalhos pioneiros foram realizados por $\mathrm{H}$. Cloos (1885-1951) e W. Riedel na década de 1920, e tinham como corpo de prova camadas de argila sobre duas tábuas adjacentes que deslizavam uma em relação à outra (Fig. 13a). Os resultados obtidos por Riedel são apresentados por Price \& Cosgrove (1990). O movimento das tábuas gera na cobertura de argila uma zona de cisalhamento a qual, em perfil, exibe uma forma de $\mathrm{V}$, com o vértice sobre a "falha do embasamento" (Fig. 13a). Isto é, grosseiramente, o que acontece na crosta quando há uma falha direcional do embasamento e que, em direção a camadas mais rasas e menos competentes - como rochas sedimentares, por exemplo - a mesma se ramifica em vários segmentos, na forma 


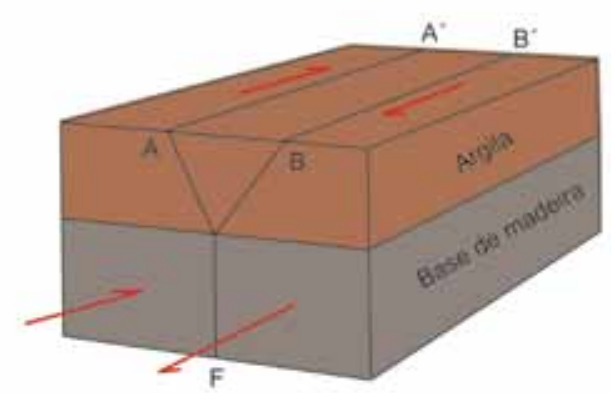

b.

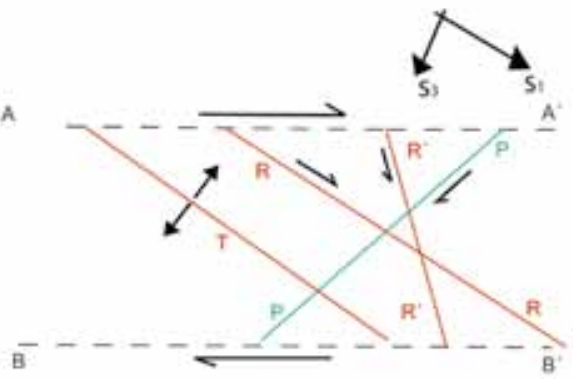

Figura 13. Ilustração dos experimentos de cisalhamento de Cloos e Riedel. (a) Esquema do experimento, em que um bloco de argila é colocado sobre um "embasamento" constituído por dois blocos de madeira que apresentam movimento relativo direcional segundo o plano F. (b) Croqui da vista em planta da zona de cisalhamento gerada na argila, mostrando a formação dos sistemas de falhas R (sintético) e R' (antitético) e de juntas T; o sistema de falhas $P$ foi identificado posteriormente por Tchalenko; $\mathrm{S}=$ sigma (Modif. Price \& Cosgrove 1990)

de um leque, como será visto posteriormente. Dentro da zona de cisalhamento formam-se juntas e falhas (Fig. 13b). As falhas formadas são conjugadas, sendo denominadas posteriormente de $\mathrm{Re}$ R' - em homenagem a Riedel (Fig. 13b). O sistema $\mathrm{R}$ apresenta movimento no mesmo sentido em relação à zona de cisalhamento e R', movimento em sentido oposto. Em geral somente R evolui; quando R' também se desenvolve efetivamente este sistema sofre rotação, sendo finalmente abandonado. Este é um ponto importante, o qual sugere que, no campo, somente o sistema $\mathrm{R}$ possa ser identificado com confiabilidade. Na década de 1960, J. S. Tchalenko realizou experimentos semelhantes e detectou a presença de um sistema P, oblíquo a $\mathrm{R}$ e $\mathrm{R}^{\prime}$ e com deslocamento no mesmo sentido da falha principal (Fig. 13b).

\section{Sistemas de falhas}

Uma vez formadas, as falhas tendem a se organizar em sistemas que são reconhecidos em mega-escala e meso-escala. Os primeiros são observáveis por meio de técnicas de sensoriamento remoto e geofísica. A meso-escala corresponde às observações em afloramento.

Para a compreensão de como esses sistemas evoluíram no tempo e no espaço, o conhecimento desenvolvido em mecânica de fraturas é fundamental. Porém, algumas ressalvas devem ser feitas quanto à relação entre as observações de laboratório em ensaios e modelos reduzidos. Embora na Natureza haja padrões que se repitam em diferentes escalas, isto não deve ser tomado como regra geral uma vez que, modificando-se a escala do sistema também são modificadas as condições ambientais. Por exemplo, os ensaios de cisalhamento puro podem simular tensões semelhantes às da crosta terrestre; todavia, não se pode reproduzir realisticamente todo um ambiente profundo em termos de temperatura, pressão e composição dos fluidos, ocorrência ou não de fusão parcial etc. E, principalmente, não se pode simular o tempo. Uma deformação que pode ser obtida no laboratório em minutos ou horas leva muitas vezes milhares ou milhões de anos para acontecer com as rochas na Natureza, e durante esse tempo as condições ambientais não permanecerão as mesmas.

Outro aspecto importante diz respeito às condições de contorno. Estruturas, estratificações, zonas alteradas, geometria de corpos rochosos e outros aspectos influenciam o estilo das estruturas geradas e o seu padrão em mega-escala não será o mesmo que aquele obtido em modelo reduzido. Ainda assim, os ensaios são um ponto de partida importante, sem os quais a geologia estrutural seria especulativa.

As observações feitas em mega-escala são realizadas por técnicas de sensoriamento remoto e geofísica, retroalimentando-se com o mapeamento geológico. O estudo nesta escala permite associar os sistemas de falhas ao campo de tensões regional, sendo este, em última análise, produzido pela interação entre as placas tectônicas.

$\mathrm{Na}$ meso-escala, que envolve os estudos de afloramento, deve-se ter cuidado na relação dos sistemas observados com os sistemas regionais. Como será visto na sequência, grandes sistemas de 


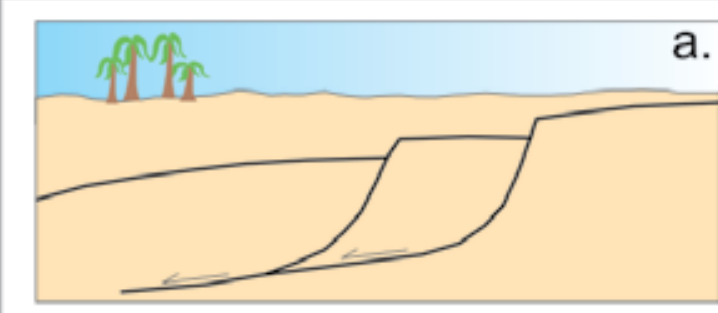

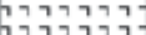

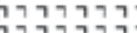

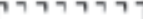
sal

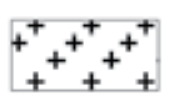

embasamento cristalino
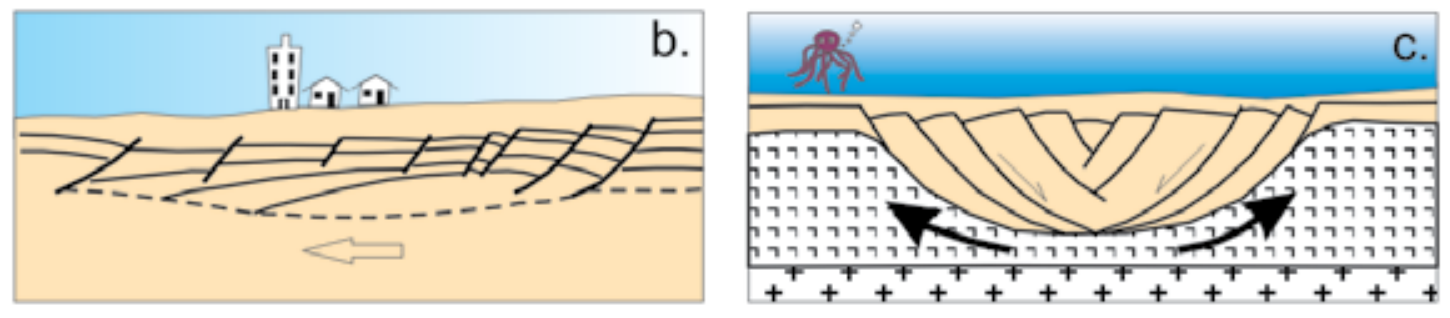

Figura 14. Estilos de sistemas de falhas distensionais de acordo com o nível crustal. (a) Movimentação somente nas camadas rasas, sem afetar o embasamento. (b) Movimentação do embasamento, gerando falhas distensionais em níveis mais rasos. (c) Movimentação de escape de sal, gerando extensão em camadas mais rasas. Modificado de Mandl (1988)

falhas gerados sob um campo de tensões regional produzem campos de tensões locais. Estes não são incompatíveis com os regionais, porém as estruturas dominantes serão outras e o regime tectônico poderá variar.

\subsection{Sistemas de falhas distensionais}

As grandes falhas distensionais são formadas em regiões dominadas por uma tração remota, que pode ser, por exemplo, uma separação entre placas. Dessa forma, a tração remota $\left(\sigma_{3}\right)$ é horizontal, assim como $\sigma_{2}$. Como a movimentação dessas falhas é no sentido da gravidade, $\sigma_{1}$ é vertical. Estes sistemas produzem as bacias do tipo rifte e alguns tipos de vulcanismo. A abertura dos oceanos se dá a partir de sistemas distensionais.

Mandl (1988) definiu os sistemas distensionais com base no nível crustal: (i) extensão restrita a camadas rasas, com as falhas normais horizontalizando-se em direção a uma superfície de descolamento inferior (Fig. 14a), e (ii) extensão produzida a partir de movimentação do substrato, refletindo-se como falhas normais nas camadas mais superficiais (Fig. 14b,c).

Do ponto de vista geométrico, ao serem observados em planta, os sistemas de falhas distensionais podem ser anastomosados ou sub-paralelos, apresentando falhas de transferência em alto ângulo ou perpendiculares à falha principal (Fig. 15). As falhas de transferência se formam pela ruptura de blocos durante a evolução da distensão.

Pela observação de sistemas naturais, com o acréscimo da distensão há aumento no comprimento médio das falhas, no número de falhas do sistema e no processo de ligação de falhas (Ackermann et al. 2001). Em escala totalmente diferente, o processo é similar ao de propagação e ligação de microfissuras.

A falha Murchison-Statfjord North, no Mar do Norte, é um exemplo de estrutura de $25 \mathrm{~km}$ de comprimento que se originou pela ligação de segmentos iniciais com até $4 \mathrm{~km}$ de comprimento. Um modelo de evolução desta falha foi apresentado por Young et al. (2001). Inicialmente isolados (Fig. 16a), os segmentos colineares menores ligaram-se ao longo da direção da zona de falha, formando dois segmentos mais longos, paralelos e não-colineares com aproximadamente $9 \mathrm{~km}$ de extensão, separados por uma rampa de revezamento ${ }^{8}$ (Fig. 16b). Com a continuidade dos movimentos das falhas, a rampa foi rompida, com a ligação passando a ocorrer por uma falha de transferência (Young et al. 2001) (Fig. 16c). A Figura 17 mostra um modelo reduzido em abatimento de solo, correspondente ao estágio 16b.

Tomando como exemplo o sistema descrito por Young et al. (2001), a falha de transferência terá movimentação vertical apenas se a falha normal principal também tiver mergulho vertical. Caso

8 Tradução livre de relay ramp. 


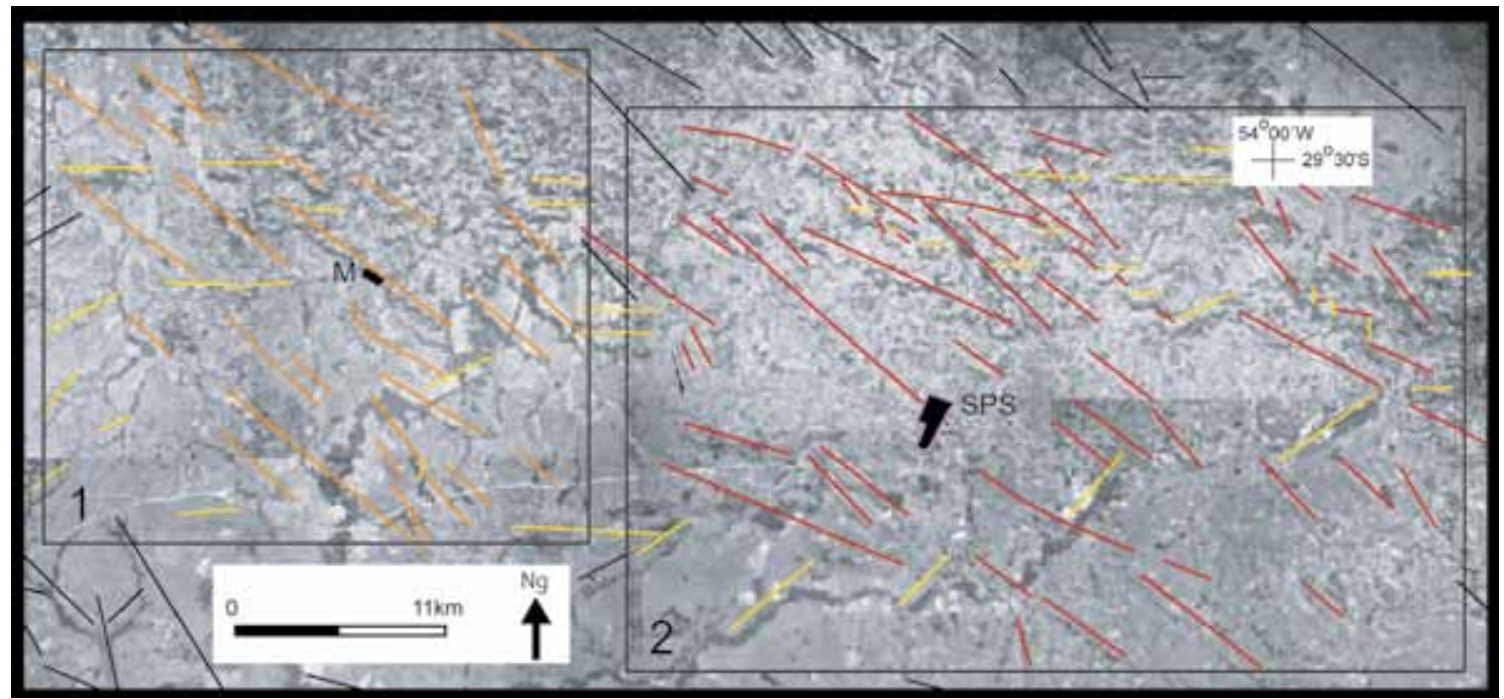

Figura 15. Fotomosaico da região central do Rio Grande do Sul, onde afloram rochas sedimentares e vulcânicas mesozóicas da Bacia do Paraná, a qual foi afetada pela tectônica distensional da abertura do Atlântico Sul. Na área 1, os lineamentos em laranja são falhas normais sub-paralelas. $\mathrm{Na}$ área 2, os lineamentos marcados em vermelho são falhas normais anastomosadas. Os lineamentos em amarelo são falhas de transferência ligando segmentos de falhas normais. SPS = Cidade de São Pedro do Sul, M = Cidade de Mata

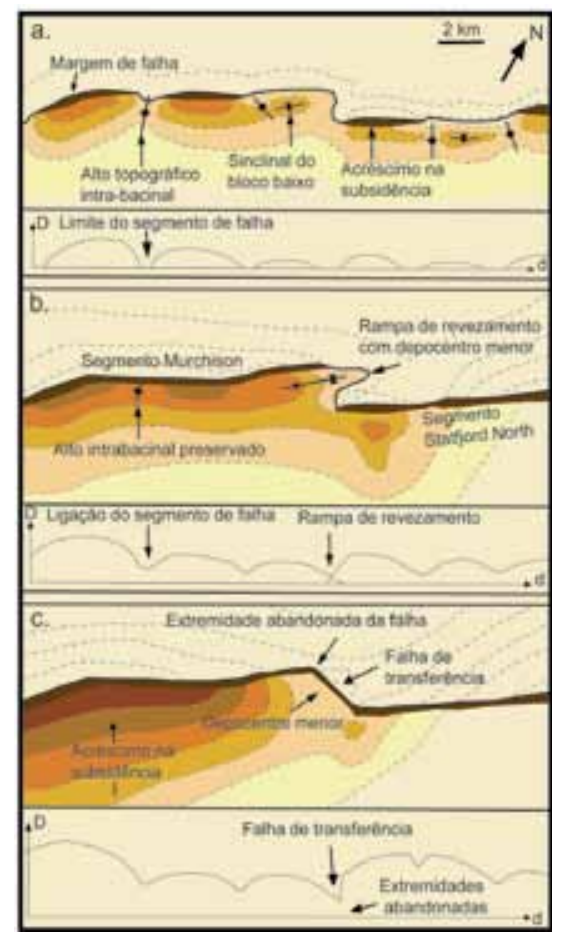

Figura 16. Esquema mostrando os três principais estágios evolutivos da falha Murchison-Statfjord North. (a) segmentos isolados de falhas, (b) ligação dos segmentos colineares resultando em duas zonas de falha paralelas separadas por uma rampa de revezamento, (c) ruptura da rampa de substituição em uma falha de transferência e formação de uma única zona de falha (Modif. Young et al. 2001)

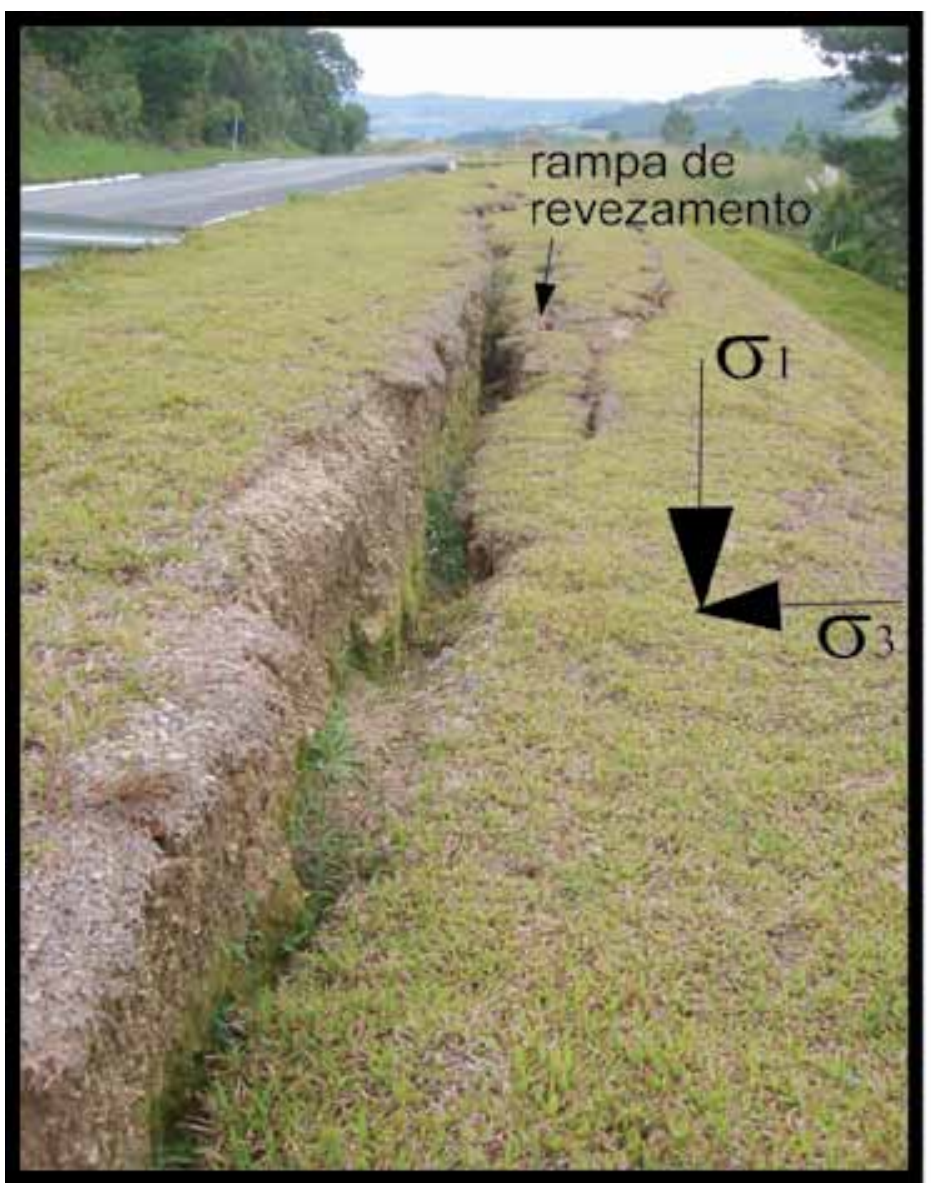

Figura 17. Modelo reduzido do estágio (b) da Figura 16 em degraus de abatimento de substrato de rodovia (Alfredo Wagner, SC) 


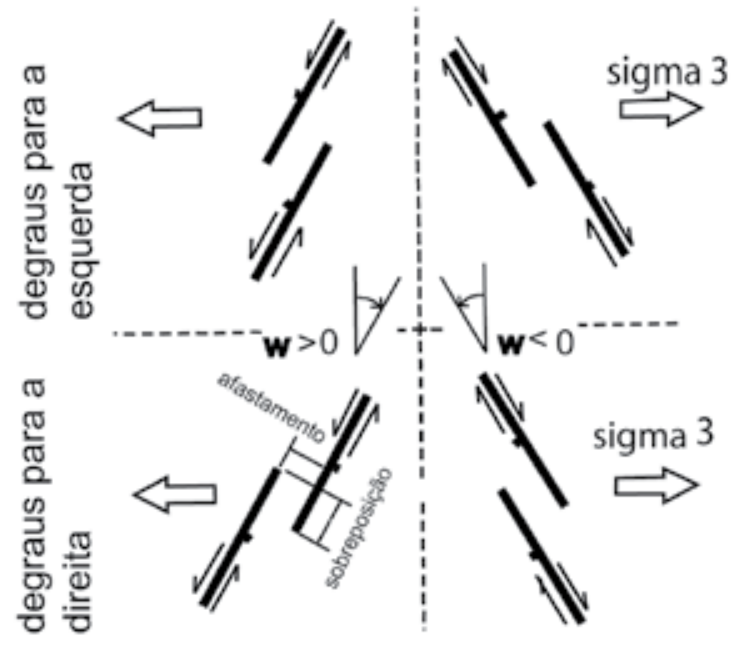

Figura 18. Possíveis movimentações do componente direcional de falhas oblíquas dispostas en échelon. $\mathrm{Sh}=$ menor compressão horizontal. $\omega$ é o ângulo entre a linha imaginária perpendicular a $\sigma 3$ e a direção das falhas (Modif. Crider 2001)

contrário, ela será oblíqua e quanto mais suave for o mergulho da falha principal, mais se afastará da vertical o deslocamento da falha de transferência. Em trabalho de campo, uma falha deste tipo pode dar a impressão errônea de que o sistema de falhas principal é transcorrente.

Outra situação também pode produzir falhas oblíquas em sistemas distensionais. Quando determinadas falhas são oblíquas à tração remota $\left(\sigma_{3}\right)$, ocorre um componente significativo de deslocamento direcional (Crider 2001). A Figura 18 mostra as possíveis combinações de falhas oblíquas, as quais são dispostas en échelon de acordo com Crider (2001). Na metade superior da figura estão as falhas com degraus para a esquerda e, na metade inferior, as falhas com degraus para a direita. $\mathrm{O}$ ângulo $\omega$ representa o desvio existente entre uma linha imaginária perpendicular a $\sigma_{3}$ e a orientação das falhas en échelon, contado a partir da linha imaginária. Se $\omega>0$, o componente horizontal do deslocamento será sinistral, e se $\omega<0$, o componente horizontal será dextral.

\subsection{Sistemas de falhas compressionais}

Em regiões da crosta em que há encurtamento, como em complexos colisionais, o eixo da tensão principal máxima $\left(\sigma_{1}\right)$ é horizontal e paralelo ao encurtamento. Já a tensão principal mínima $\left(\sigma_{3}\right)$ é vertical, gerando alívio de tensão na vertical. Em última análise, a disposição do campo de tensões é responsável pelo soerguimento das áreas montanhosas.

Segundo Mandl (1988) há dois tipos básicos de sistemas compressionais, de acordo com a profundidade da crosta em que o processo atua mais efetivamente. Em sistemas compressionais rasos, o encurtamento se dá nas camadas mais superficiais, sem afetar as rochas do embasamento. As falhas formadas partem de uma superfície de descolamento aproximadamente horizontal (Fig. 19a), que pode ocorrer em variadas profundidades, até o limite rúptil-dúctil da crosta. Já em sistemas profundos, o encurtamento domina no embasamento profundo, gerando soerguimento ao longo de falhas subverticais (Fig. 19b).

Em ambientes compressionais, os sistemas de falhas são dominados pelas falhas de empurrão, que apresentam baixo ângulo de mergulho quando iniciadas. Utilizando-se dos conceitos da mecânica

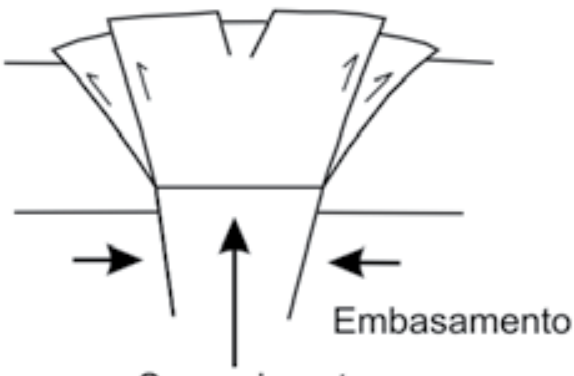

Soerguimento

Figura 19. Sistema de falhas compressionais de acordo com o ambiente crustal. (a) Sistema raso, com desenvolvimento de falhas de empurrão a partir de uma superfície de descolamento. (b) Sistema desenvolvido a partir de compressão no embasamento profundo, produzindo soerguimento por meio de falhas subverticais (Modif. Mandl 1988) 


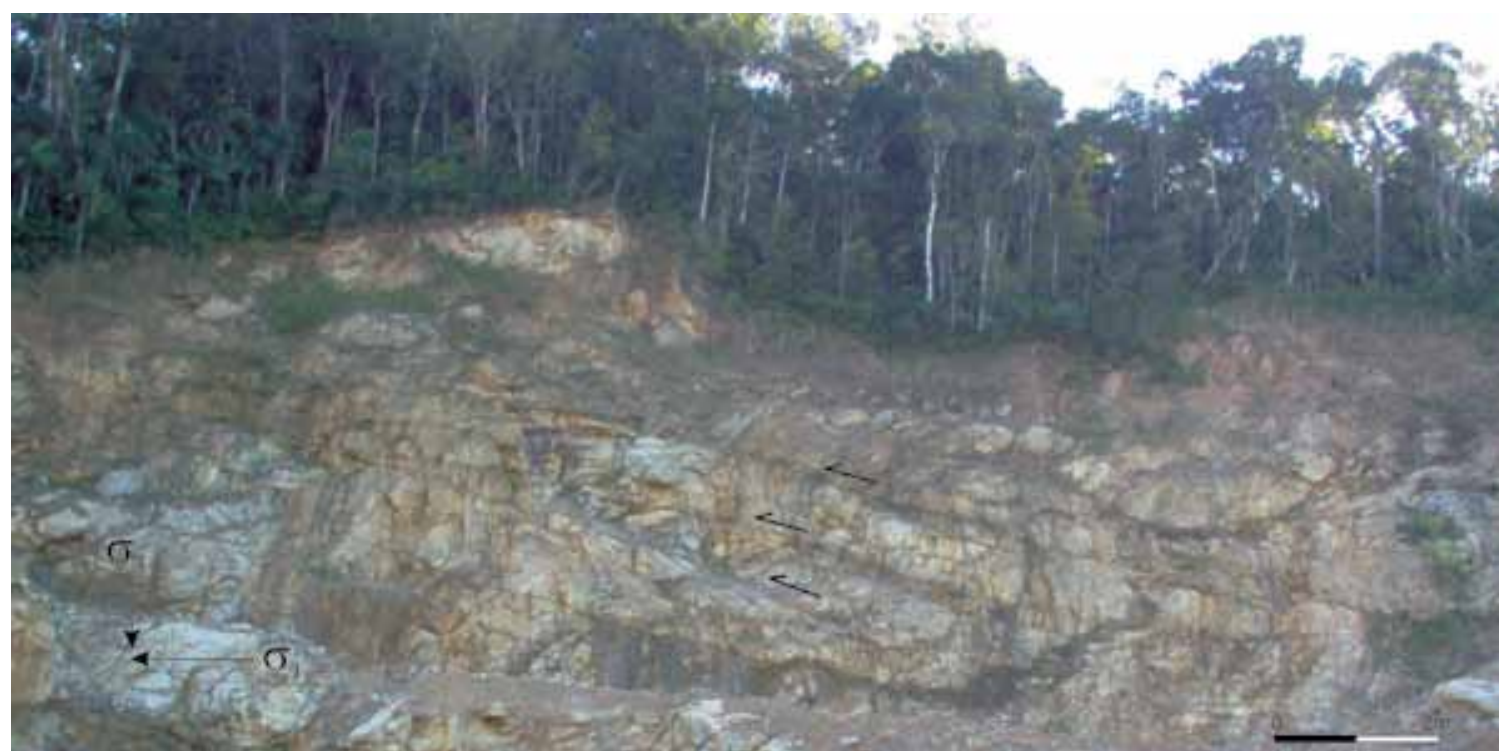

Figura 20. Sistema de falhas de empurrão. Complexo Granulítico de Santa Catarina, Paleoproterozóico (Pomerode, SC)

de fraturas, a compressão com $\sigma_{1}$ horizontal produziria um par conjugado de fraturas cuja bissetriz é igualmente vertical. De fato, essas feições podem ser observadas em sistemas naturais, mas de forma subordinada e apenas em meso-escala. Isto ocorre porque, como visto anteriormente, apenas uma

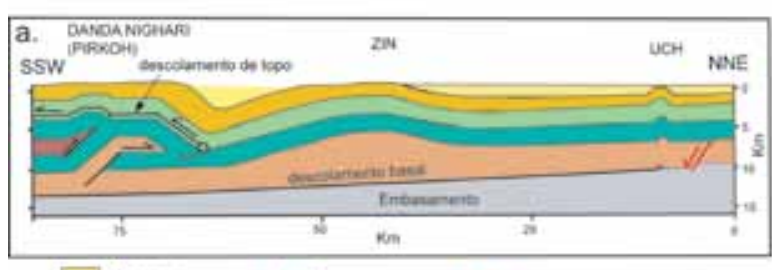

\begin{tabular}{|c|c|c|}
\hline$\square$ Neogene. & Cresaces & |Pre-Cambrano - Thásicos \\
\hline Pusogeno & Suratsico & \\
\hline
\end{tabular}

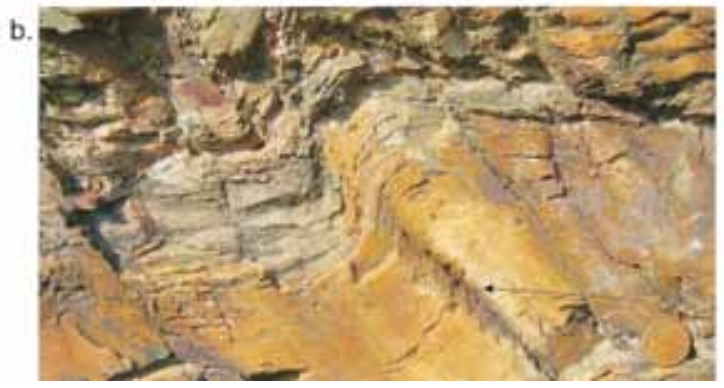

Figura 21. (a) Desenho esquemático modificado de uma seção de Jadoon et al. (1993) no sistema de empurrões Sulaiman, Paquistão. Observa-se uma dobra de descolamento na extremidade de uma estrutura duplex. ED = eixo da dobra. (b) Falha de empurrão em xisto (indicada pela seta), formada pela ruptura da zona de charneira de uma dobra. A moeda tem $2 \mathrm{~cm}$ de diâmetro (Complexo Variscano, Devoniano, Huelva, Espanha) fratura do par evolui como falha, e vai crescendo pela ligação com outros segmentos. Sob esforços compressivos, o plano do par conjugado que evolui é aquele que se desloca para cima, no sentido da menor pressão litostática, gerando os sistemas de falhas de empurrão imbricadas, que mergulham em um único sentido, contrário à tensão principal (Fig. 20).

Quando vistos em planta, os sistemas de empurrão são em geral curvilíneos e paralelos. Estes sistemas muitas vezes se ligam em padróes grosseiramente bifurcados e anastomosados, ou por intermédio de falhas de transferência altamente oblíquas, as rampas laterais (Davison 1994). Aqui, novamente pode-se confundir com um ambiente transcorrente se uma falha de transferência for observada isoladamente.

Observa-se que as falhas de empurrão se ligam em superfícies de descolamento, que normalmente aproveitam horizontes litológicos com baixa resistência ao cisalhamento (Mandl 1988, Davison 1994). Uma questão bastante debatida refere-se à relação temporal entre a formação de cada falha individual e a formação da superfície de descolamento. Segundo Davison (1994), as falhas podem se propagar para cima a partir de uma superfície basal, ou podem se iniciar individualmente em horizontes acima da futura superfície de descolamento, propagando-se para baixo até se ligarem.

As falhas que se ligam na parte inferior podem se ligar também em uma superfície de descolamento superior, formando estruturas com geometria 


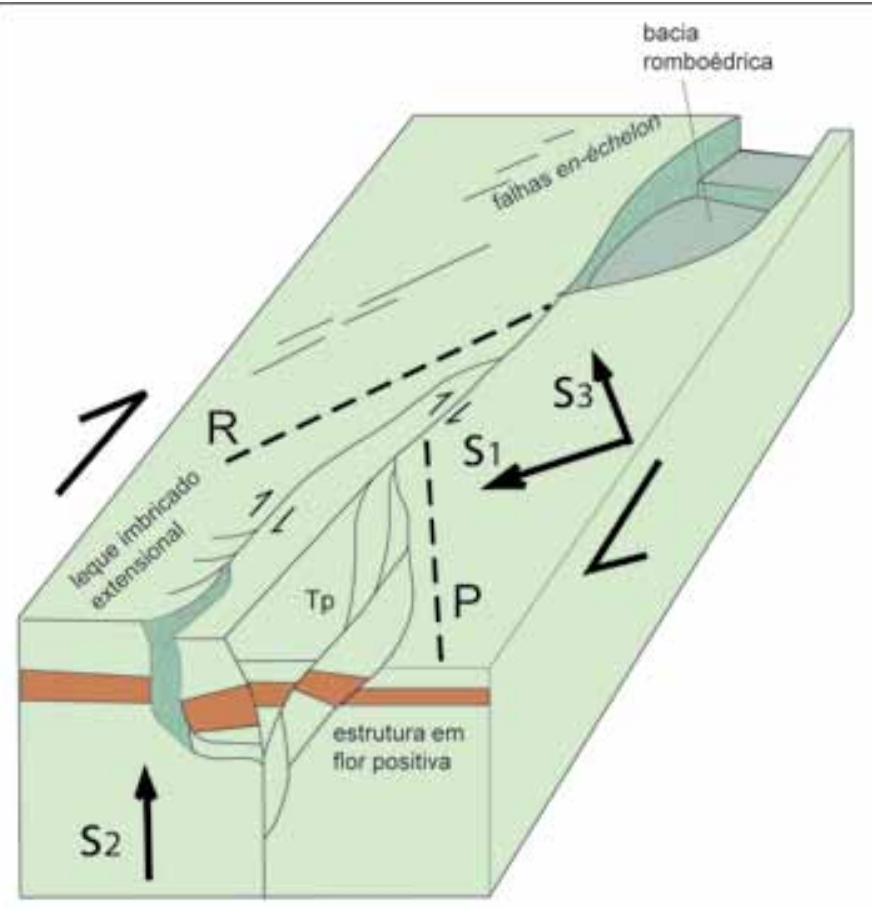

Figura 22. Sistema de falhas direcionais. Bloco-diagrama com as principais feições observadas ( $\mathrm{S}=$ sigma) (modificada de Davison 1994).

sigmoidal, denominadas duplex (Davison 1994). Um exemplo natural deste tipo de estrutura é o sistema de empurrões e dobras Sulaiman, no Paquistão, descrito por Jadoon et al. (1993), no qual as falhas se desenvolveram a partir de superfície de descolamento basal, na descontinuidade existente sobre o embasamento cristalino, e se ligaram em um horizonte superior, que se utilizou de camada de folhelhos cretácicos pouco competentes (baixo valor de $\boldsymbol{T}_{0}$ ) (Fig. 21a). Outra feição observada (à esquerda na Fig. 20a) são os empurrões no sentido contrário - os retro-empurrões. Eles ocorrem em muitos sistemas compressionais de forma subordinada, e se acredita tratarem-se do par conjugado formado no cisalhamento puro.

As falhas de empurrão são intimamente associadas a dobras, e uma estrutura pode se formar a partir da outra. No exemplo da Figura 21a, o deslocamento da falha de empurrão gerou uma dobra de descolamento. A Figura 21b, por sua vez, mostra uma dobra recumbente ${ }^{9}$ que se fraturou em sua zona de charneira, produzindo uma proto-falha compressional. Numa situação como essa, uma sequência encadeada de dobras recumbentes pode produzir um sistema de falhas de empurrão.

9 Uma dobra recumbente possui plano axial deslocado em relação à vertical e zona de charneira assimétrica, inclinada no sentido do deslocamento. Este tipo de dobra é característico de ambientes dominados por cisalhamento simples.

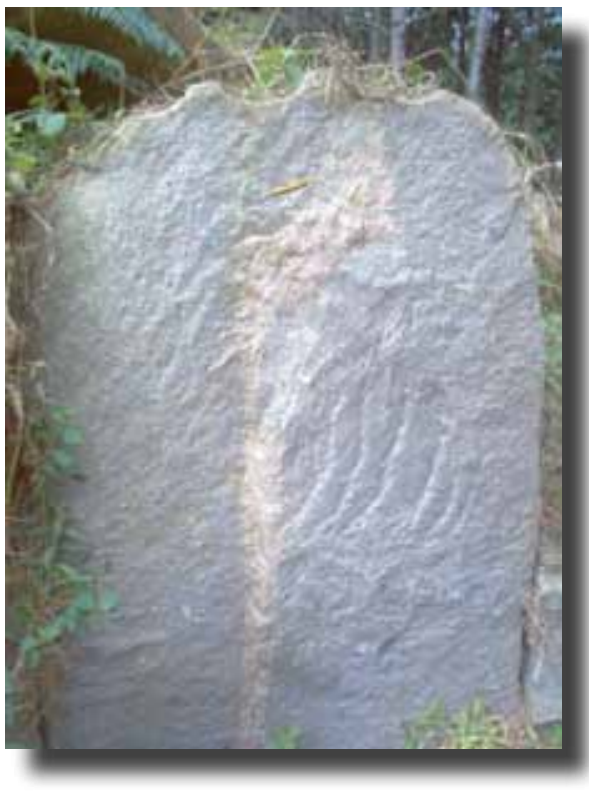

Figura 23. Detalhe de uma feição romboédrica gerada por tração associada a movimento direcional em matacão de rocha granulítica; neste caso, a "bacia" foi preenchida por minerais, predominantemente de feldspato potássico (Complexo Granulítico de Santa Catarina, Paleoproterozóico, Luís Alves, SC) A lapiseira tem $14,5 \mathrm{~cm}$ de comprimento

\subsection{Sistemas de falhas transcorrentes}

O raciocínio empregado quando da interpretação de ensaios de cisalhamento simples pode ser aplicado também na análise dos sistemas de falhas transcorrentes. Os eixos principais máximo e mínimo $\left(\sigma_{1}\right.$ e $\left.\sigma_{3}\right)$ são horizontais, e o intermediário $\left(\sigma_{2}\right)$ é vertical. Este arranjo pode produzir regimes locais distensionais e compressionais, o que pode prejudicar a interpretação do campo de tensões regional.

Quando observados em planta, os sistemas de falhas direcionais exibem um padrão anastomosado (Davison 1994). Este padrão deve-se à utilização de segmentos dos sistemas conjugados durante a fase de ligação (Davison 1994, An \& Sammis 1996), conforme discutido no capítulo anterior. A vista em planta também mostra a ocorrência de zonas de transtração e transpressão ${ }^{10}$, perpendiculares a $\sigma_{3}$ e $\sigma_{1}$, respectivamente.

Estas zonas podem ocorrer às margens da falha principal, formando bacias distensionais (grábens) e zonas com falhas de empurrão e dobras, em

10 Transtração e transpressão são, respectivamente, os nomes dados aos casos especiais de distensão e compressão associados a um sistema de falhas transcorrentes. 
ângulos oblíquos em relação à falha principal (Fig. 22). Zonas de transpressão e transtração também se formam em segmentos da falha transcorrente em que há a inflexão de sua direção, devido ao fato de que essas falhas não são necessariamente retilíneas. De acordo com o sentido do movimento em relação à direção da inflexão, poderá se desenvolver uma zona compressional soerguida por empurrões e dobramentos (Fig. 22), denominada de pop-up, ou uma zona distensional, chamada de bacia romboédrica ou de pull-apart (figuras 22, 23). Este tipo de estrutura ocorre em escalas desde microscópica até regional, neste último caso sendo muito importante para o desenvolvimento de bacias sedimentares. Em escala de afloramento estas estruturas, por serem de abertura, podem hospedar minerais ali precipitados (Fig. 23).

A vista de falhas direcionais em seções transversais mostra uma raiz principal em alto ângulo, que se divide em vários braços em direção à superfície (Davison 1994). Outra feição característica são as estruturas em flor positivas (Fig. 22). Percebe-se, neste caso, a semelhança com a geometria das falhas geradas nos ensaios de Cloos e Riedel (Fig. 13).

\section{Considerações finais}

Espera-se que este artigo cumpra seu papel de ligação entre o conhecimento da mecânica de rochas e o da geologia estrutural clássica. Procurouse fazer uma abordagem a partir dos conceitos físicos mais fundamentais, dentro de um pensamento evolucionista. Considera-se que as forças fundamentais produzem interações que se refletem em processos na crosta terrestre. Como estes processos atuam no decorrer do Tempo Geológico, seus produtos - as estruturas das rochas - se sobrepõem em uma complexidade crescente e sem retorno.

Com este quadro complexo o geólogo se depara ao estudar imagens remotas e afloramentos. O conhecimento dos processos mecânicos ao quais as rochas foram submetidas auxiliará na separação dos produtos em gerações, e assim contar a história de deformação de uma área. Como há na bibliografia excelentes descrições e interpretações das estruturas a partir de critérios geométricos, optou-se por focalizar mais a questão da mecânica de rochas, em especial como este conhecimento se liga com a geologia estrutural de campo.

\section{Agradecimentos}

Os autores agradecem a Geise de Santana dos Anjos Zerfass pela leitura crítica do manuscrito e aos revisores Álvaro Penteado Crosta e Celso Dal Ré Carneiro pelas valiosas sugestões e correção criteriosa.

\section{Referências bibliográficas}

Ackermann R.V., Schlische R.W., Withjack M.O. 2001. The geometric and statistical evolution of normal fault systems: an experimental study of the effects of mechanical layer thickness on scaling laws. J. Struct. Geol, 23:1803-1819.

An L.-J., Sammis C.G. 1996. Development of strikeslip faults: shear experiments in granular materials and clay using a new technique.J. Struct. Geol, 18(8):1061-1077.

Atkinson B.K., Meredith P.G. 1987. The theory of subcritical growth with applications to minerals and rocks. In: Atkinson B.K. ed. 1987. Fracture mechanics of rock. London: Academic Press, p. 111-166.

Belousov V.V. 1974. Geologia estructural. Moscu: Editorial Mir, $303 \mathrm{p}$.

Cajori F. 1929. A history of physics. New York: Dover Publ., 424p.

Costin L.S. 1987. Time-dependent deformation and failure. . In: Atkinson B. K. ed. 1987. Fracture mechanics of rock. London: Academic Press, p. $167-216$.

Crider J.G. 2001. Oblique slip and the geometry of normal-fault linkage: mechanics and a case study from the Basin and Range in Oregon. Journal Struc Geol, 23:1997-2009.

Davis R.O., Selvadurai A.P.S. 2002. Plasticity and Geomechanics. Cambridge: Cambridge Univ. Press. $287 \mathrm{p}$.

Davison I. 1994. Linked fault systems; distensional, strike-slip and contractional. In: Hancock, P.L. ed. 1994. Continental deformation. Oxford: Pergamon Press, p.121-142.

Einstein A., Infeld L. 1938. A evolução da Física. Rio de Janeiro: Zahar Editores. 237p.

Engelder T. 1994. Brittle crack propagation. In: Hancock P.L. ed. 1995. Continental deformation. Oxford: Pergamon Press, p. 43-52.

Grigoryev V., Myakishev G. 1967. The forces of nature. Moscow: Mir Publishers. 346p.

Hancock P.L. 1985. Brittle microtectonics: principles and practice. J. Struct. Geol, 7(3/4):437-457.

Hobbs B.E., Means W.D., Williams P.F. 1976. An outline of structural geology. New York: John Wiley \& Sons. $571 \mathrm{p}$. 
Ingraffea A.R. 1987. Theory of crack initiation and propagation in rock. In: Atkinson B. K. ed. 1987. Fracture mechanics of rock. London: Academic Press, p. 71-110.

Jadoon I.A.K., Lawrence R.D., Lilie R.J. 1993. Evolution of foreland structures: an example from the Sulaiman thrust lobe of Pakistan, southwest of the Himalayas. In: Treloar P.J., Searle M.P. eds. 1993. Himalayan tectonics. Geol. Soc. Spec. Publ., 74:589-602.

Loczy L., Ladeira E.A. 1976.J. Struct. Geol. São Paulo: Edgard Blücher. 528p.

Mandl G. 1988. Mechanics of tectonic faulting. Amsterdam: Elsevier. 407p.

Mansfield C., Cartwright J. 2001. Fault growth by linkage: observations and implications from analogue models. J. Struct. Geol, 23:745-763.

Martel S.J., Pollard D.D., Segall P. 1988. Development of simple strike-slip fault zones, Mount Abbot quadrangle, Sierra Nevada, California. Geol. Soc. Am. Bull., 100:1451-1465.

Martel S.J. 1990. Formation of compound strike-slip fault zones, Mount Abbot quadrangle, California. Journal of Structural Geology, 12(7):869-882.
Newton I. 1686. Princípios matemáticos de filosofia natural. São Paulo: Nova Stella e Editora da USP. 292p.

Pollard D.D., Aydin A. 1988. Progress in understanding jointing over the past century. Geol. Soc. Ame. Bull., 100:1181-1204.

Pollard D.D., Fletcher R.C. 2005. Fundamentals of Structural Geology. Cambridge: Cambridge University Press. 500 p.

Price N.J., Cosgrove J.W. 1990. Analysis of geological structures. Cambridge: Cambridge University Press. 502 p.

Ramsay J.G., Huber M.I. 1987. The techniques of modern structural geology. London: Academic Press. 700p.

Willemse E.J.M., Peacock D.C.P., Aydin A. 1997. Nucleation and growth of strike-slip faults in limestones from Somerset, U. K. J. Struct. Geol, 19(12):1461-1477.

Young M.J., Gawthorpe R.L., Hardy S. 2001. Growth and linkage of a segmented normal fault zone; the Late Jurassic Murchison-Statfjord North Fault, northern North Sea.J. Struct. Geol, 23:1933-1952. 